\title{
Identifying SARS-CoV-2 antiviral compounds by screening for small molecule inhibitors of nsp13 helicase
}

\author{
Jingkun Zeng ${ }^{1, \star}$, Florian Weissmann ${ }^{1, \star}$, Agustina P. Bertolin ${ }^{1, \star}$, Viktor Posse ${ }^{1}$, Berta Canal ${ }^{1}$, Rachel Ulferts ${ }^{2}$, \\ Mary $\mathbf{W u}^{3}$, Ruth Harvey ${ }^{4}$, Saira Hussain ${ }^{4}$, Jennifer C. Milligan', Chloe Roustan ${ }^{5}$, Annabel Borg ${ }^{5}$, \\ Laura McCoy ${ }^{6}$, Lucy S. Drury', Svend Kjaer ${ }^{5}$, John McCauley ${ }^{4}$, Michael Howell ${ }^{3}$, Rupert Beale ${ }^{2}$ \\ and $(1)$ John F.X. Diffley ${ }^{1}$
}

\begin{abstract}
${ }^{1}$ Chromosome Replication Laboratory, The Francis Crick Institute, 1 Midland Road, London NW1 1AT, U.K.; ${ }^{2}$ Cell Biology of Infection Laboratory, The Francis Crick Institute, 1 Midland Road, London NW1 1AT, U.K.; ${ }^{3}$ High Throughput Screening, The Francis Crick Institute, 1 Midland Road, London NW1 1AT, U.K.; ${ }^{4}$ World Influenza Centre, The Francis Crick Institute, 1 Midland Road, London NW1 1AT, U.K.; ${ }^{5}$ Structural Biology, The Francis Crick Institute, 1 Midland Road, London NW1 1AT, U.K.; ${ }^{6}$ Division of Infection and Immunity, University College London, London WC1E 6BT, U.K.
\end{abstract}

Correspondence: John F.X Diffley (john.diffley@crick.ac.uk)

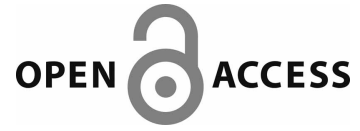

${ }^{*}$ These authors contributed equally to this work.

Received: 22 March 2021 Revised: 5 May 2021 Accepted: 10 May 2021

Accepted Manuscript online: 11 May 2021

Version of Record published: 2 July 2021
The coronavirus disease 2019 (COVID-19) pandemic, which is caused by severe acute respiratory syndrome coronavirus 2 (SARS-CoV-2), is a global public health challenge. While the efficacy of vaccines against emerging and future virus variants remains unclear, there is a need for therapeutics. Repurposing existing drugs represents a promising and potentially rapid opportunity to find novel antivirals against SARS-CoV-2. The virus encodes at least nine enzymatic activities that are potential drug targets. Here, we have expressed, purified and developed enzymatic assays for SARS-CoV-2 nsp13 helicase, a viral replication protein that is essential for the coronavirus life cycle. We screened a custom chemical library of over 5000 previously characterized pharmaceuticals for nsp13 inhibitors using a fluorescence resonance energy transfer-based high-throughput screening approach. From this, we have identified FPA-124 and several suramin-related compounds as novel inhibitors of nsp13 helicase activity in vitro. We describe the efficacy of these drugs using assays we developed to monitor SARS-CoV-2 growth in Vero E6 cells.

\section{Introduction}

More than 100 million people have been infected and more than 2.5 million people have died worldwide due to the COVID-19 pandemic as of late February 2021 [1]. The number of infections continues to rise, with more than 150000 daily infections globally, highlighting the importance of developing effective vaccines and therapeutics for the prevention and treatment of COVID-19. Vaccines are under mass roll-out nevertheless concerns over potentially vaccine-resistant variants have been growing. It has been shown in cell culture experiments that the virus has the potential to evolve mutant strains that can evade neutralizing antibodies produced by the body to combat infections [2], and reports have emerged that certain variants could cause re-infections [3]. Many of the vaccines being used, e.g. the COVID-19 vaccines produced by Pfizer, Moderna and AstraZeneca-Oxford, target the spike protein on the surface of SARS-CoV-2 [4]. Multiple mutations of the spike protein have been found around the globe [5]. Although there is no clear evidence of vaccine-evading variants yet, vaccines against rapidly evolving structural proteins might not protect against all newly emerging strains and are unlikely to have pan-coronavirus efficacy. With these uncertainties regarding SARS-CoV-2 vaccines, multiple layers of protection and treatment against COVID-19 are needed including the identification of therapeutic drugs that can interfere with viral entry or viral propagation. Nonetheless, therapeutic options for COVID-19 are currently limited. De novo development of 
antiviral therapies generally requires between 10 and 17 years [6]. The repurposing of drugs originally developed for other uses could provide a practical approach for the fast identification, characterization and deployment of antiviral treatments [6,7]. The repurposing of approved or investigational drugs exploits existing detailed information on drug chemistry together with human pharmacology and toxicology, allowing rapid clinical trials and regulatory review [6]. This strategy has proven useful so far, with a few repurposed medicines having been authorized by different regulatory agencies to treat COVID-19, such as remdesivir, an antiviral developed to treat Ebola [8,9]. Remdesivir is a pro-drug inhibitor of the RNA-dependent RNA polymerase (RdRp) that shows inhibitory activity against all three strains, SARS-CoV-1, MERS-CoV and SARS-CoV-2, of the coronavirus outbreaks in this century [10-12]. Drug resistance to monotherapies may develop rapidly, particularly in RNA viruses where mutations occur frequently, thus it would be useful to have multiple antiviral drugs $[13,14]$.

SARS-CoV-2 is a positive-sense single-stranded RNA virus that encodes at least nine enzymatic activities in two overlapping large polyproteins ppla and pp1ab $[15,16]$. Once expressed in the host cell, pp1a and pplab are processed by virus-encoded proteases into 16 non-structural proteins (nsps) [15,16]. Coronavirus nsp13, one of the non-structural proteins, is a superfamily 1B (SF1B) helicase that can unwind DNA or RNA in an NTP-dependent manner with a $5^{\prime}$ to $3^{\prime}$ polarity [17-21]. Moreover, nsp13 harbours RNA $5^{\prime}$-triphosphatase activity that could play a role in viral $5^{\prime}$ RNA capping $[18,20,22]$. Nsp13 is highly conserved among SARS-like coronaviruses with $99.8 \%$ sequence identity (600 out of 601 amino acids) between SARS-CoV-1 and SARS-CoV-2 [23]. Importantly, nsp13 is a key component of the viral replication-transcription complex (RTC) and is indispensable for the coronavirus life cycle, making it a promising target for pan-coronavirus antivirals [24-27].

As part of a larger project to identify small-molecule inhibitors of all SARS-CoV-2 enzymes, we report the development of a high-throughput fluorescence resonance energy transfer (FRET)-based assay for nsp13 helicase activity in vitro. We used this assay to screen a custom compound library of over 5000 previously characterized pharmaceuticals. We identify FPA-124 and suramin-like compounds as novel nsp13 inhibitors that also show antiviral activity in a cell-based viral proliferation assay.

\section{Results}

\section{Protein expression and purification}

For SARS-CoV-1 nsp13, it has previously been shown that GST-tagged nsp13 expressed in insect cells is more active than MBP- or 6xHis-tagged nsp13 expressed in bacteria [28,29]. Therefore, we used a baculovirus-insect cell expression system to express and purify two differently tagged SARS-CoV-2 nsp13 versions, GST-nsp13 and $3 x_{\text {Flag-His }}$-nsp13 (FH-nsp13). Both nsp13 variants were purified using affinity chromatography based on GST or the 3xFlag tag followed by gel filtration (Figure 1A and Supplementary Figure S1A,B).

\section{Development of a FRET-based helicase assay}

Coronavirus helicases unwind either double-stranded DNA or RNA, translocate in a $5^{\prime}$-to- $3^{\prime}$ direction and require a $5^{\prime}$-overhang to load on their substrate and start duplex unwinding [18-20,28,30]. To monitor the unwinding activity of nsp13, we designed a FRET-based helicase assay suitable for high-throughput screening (HTS). The substrate consisted of a 35 nucleotide (nt) DNA strand hybridized to a second 15 nt complementary DNA, leaving a $20 \mathrm{nt}$ single-stranded overhang at the $5^{\prime}$ end. A Cy3 fluorescent moiety and a non-emitting dark quencher (BHQ-2) were present at the $5^{\prime}$ and $3^{\prime}$ end of the duplex region, respectively, so the Cy3 would be quenched until nsp13 unwinds the strands, freeing the fluorophore from quenching and producing fluorescence (Figure 1B). Indeed, Cy3 fluorescence was quenched by the BHQ-2 present on the opposite strand (Supplementary Figure S1C), and this quenching was lost following incubation with nsp13 (Figure 1C). A 5-fold excess of competitor DNA strand was added to prevent substrate re-annealing (Supplementary Figure S1D). This competitor strand captures one of the unwound strands (Cy3 strand) generating a DNA duplex without $5^{\prime}$ overhang, and hence, a very poor substrate for nsp13 (Figure 1B). Both enzyme preparations, FH-nsp13 and GST-nsp13, showed similar levels of DNA substrate unwinding after a 20-min incubation on ice (Figure 1C). Due to the higher protein yields obtained after FH-nsp13 expression and purification compared with the GST version, we chose FH-nsp13 for all subsequent experiments. Unwinding increased approximately linearly over the first 5-10 minutes of the reaction at FH-nsp13 concentrations of 1-4 nM (Figure 1D). We also found nsp13 was not able to unwind a similar DNA substrate with a $3^{\prime}$ overhang (Supplementary Figure S1E,F), consistent with other coronavirus helicases [18-20,31]. FH-nsp13 unwinding activity was also observed in a 
A

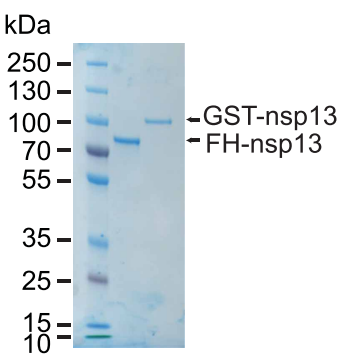

C

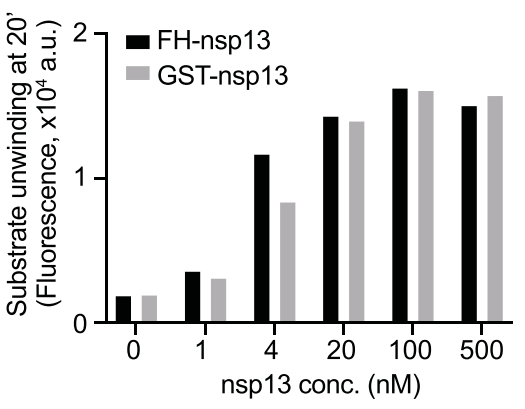

B FRET-based helicase assay
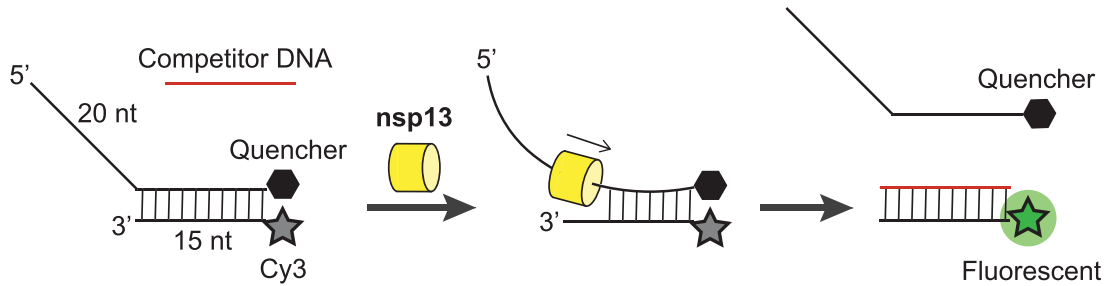

D

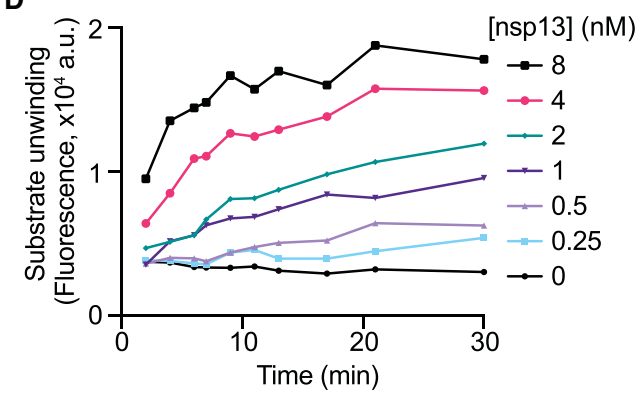

Figure 1. Development of a FRET-based SARS-CoV-2 nsp13 helicase assay.

(A) Purified 3xFlag-His 6 -nsp13 (FH-nsp13) and GST-nsp13 analysed by SDS-PAGE and Coomassie staining. (B) Schematic diagram illustrating the FRET-based nsp13 helicase assay. A nucleic acid substrate with a $5^{\prime}$ overhang is generated by annealing a fluorophore-labelled oligonucleotide (Cy3 strand) with a quencher-containing oligonucleotide (BHQ-2 strand). Nsp13 helicase activity displaces the BHQ-2 strand generating a fluorescent signal. A competitor oligonucleotide captures the free Cy3 strand preventing substrate re-annealing. The Cy3-competitor hybrid product does not contain a $5^{\prime}$ overhang and is no longer a good substrate for nsp13. (C) FH-nsp13 and GST-nsp13 were incubated with 50 nM DNA substrate and 2 mM ATP at the indicated concentrations for $20 \mathrm{~min}$ on ice and Cy3 signal was measured (a.u. = arbitrary units). (D) Time course experiment using FH-nsp13 as indicated, 50 nM DNA substrate, and 2 mM ATP (a.u. = arbitrary units).

gel-based assay using a radiolabelled DNA substrate with the same DNA sequence as the substrate used in the FRET-based assay (Supplementary Figure S1G). After 20 min the substrate was almost completely unwound in the gel-based assay, which suggests the saturation of fluorescence signals observed in Figure 1D under similar conditions could be due to complete substrate unwinding.

To determine the optimal concentration of substrates for best sensitivity in nsp13 inhibitor screening, we determined the Michaelis-Menten constants $\left(K_{\mathrm{m}}\right)$ for ATP and nucleic acid substrates. It has been shown by others that coronavirus helicases lack nucleic acid specificity, being capable of unwinding DNA and RNA [18-21]. We synthesized an RNA substrate of identical sequence as its DNA counterpart and tested nsp13 activity. Nsp13 exhibited similar activity on both the DNA and RNA substrates, with a higher apparent $K_{\mathrm{m}}$ value for the DNA $\left(K_{\mathrm{m}}=2.6 \mu \mathrm{M}\right.$, Figure $2 \mathrm{~A}$ and Supplementary Figure S2A) than the RNA substrate $\left(K_{\mathrm{m}}=1.0 \mu \mathrm{M}\right.$, Figure $2 \mathrm{~B}$ and Supplementary Figure S2B). The unwinding of the RNA substrate by FH-nsp13 was also observed in a gel-based assay (Supplementary Figure S2C). The $K_{\mathrm{m}}$ values obtained for ATP were similar with either the DNA $\left(K_{\mathrm{m}}=0.11 \mathrm{mM}\right.$, Figure $2 \mathrm{C}$ and Supplementary Figure S2D) or the RNA substrate $\left(K_{\mathrm{m}}=\right.$ $0.13 \mathrm{mM}$, Figure 2D and Supplementary Figure S2F) in the reaction. As expected, in the absence of ATP, both substrates (DNA/RNA) presented only background levels of fluorescence (Supplementary Figure S2D,E). The DNA substrate was used in the subsequent high-throughput screen (HTS) because it is more stable and was easier to source during the U.K.'s first national lockdown. For HTS reactions, we chose to use an ATP concentration close to the $K_{\mathrm{m}}$ value of $100 \mu \mathrm{M}$, and a DNA substrate concentration of $180 \mathrm{nM}$ capable of producing strong fluorescent signals. We used $3 \mathrm{nM}$ nsp13 in HTS reactions after performing an enzyme titration around the final DNA substrate and ATP concentrations (Figure 2E). We confirmed that nsp13 activity was not affected by DMSO at concentrations up to $5 \%$ as the chemical compounds to be screened were dissolved in DMSO (Supplementary Figure S2F). 


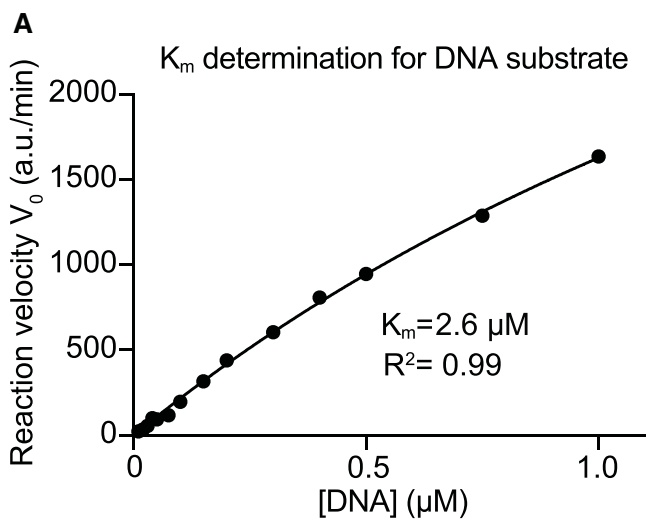

A

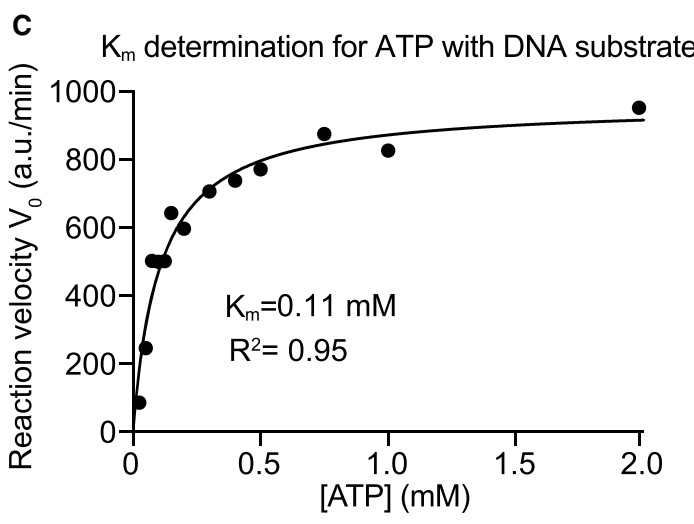

B
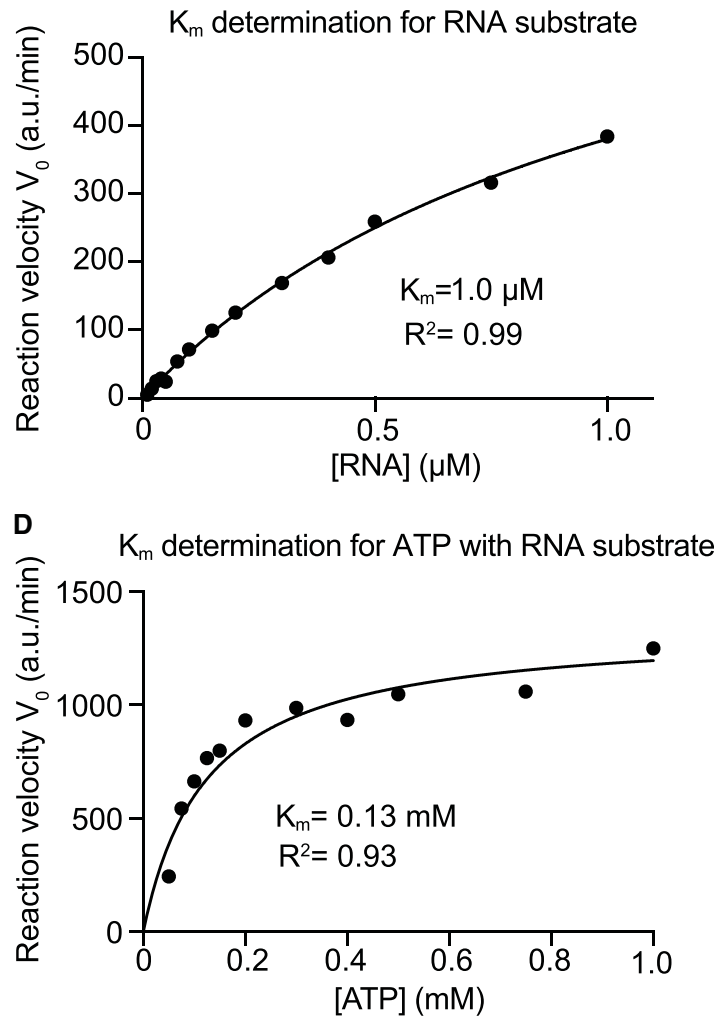

Figure 2. Enzyme kinetics and optimization of assay conditions for high-throughput screening.

(A) Michaelis-Menten kinetics $\left(K_{m}\right)$ for the DNA substrate. To obtain the Michaelis constant $\left(K_{m}\right)$ of nsp13 for DNA, initial reaction velocities $\left(V_{0}\right)$ were determined at various DNA substrate concentrations. The experiment was performed using $1 \mathrm{nM}$ FH-nsp13 and $1 \mathrm{mM}$ ATP (see Supplementary Figure S2A). Reaction velocities did not approach saturation at the highest concentration tested and therefore the apparent $K_{\mathrm{m}}$ was estimated based on an incomplete dataset. The data were fitted using the Michaelis-Menten equation (a.u./min: arbitrary units per min) using Prism software. (B) $K_{\mathrm{m}}$ for the RNA substrate. $K_{\mathrm{m}}$ was estimated based on an incomplete dataset. The experiment was performed as in (A) using $1 \mathrm{nM} \mathrm{FH-nsp13} \mathrm{and} 1 \mathrm{mM}$ ATP (see Supplementary Figure S2B). (C) $K_{\mathrm{m}}$ for ATP with the DNA substrate in reaction. The experiment was performed as in (A) using 2 nM FH-nsp13 and 200 nM DNA substrate (see Supplementary Figure S2D). (D) $K_{m}$ for ATP with the RNA substrate in reaction. The experiment was performed as in (A) using $3 \mathrm{nM}$ FH-nsp13 and $200 \mathrm{nM}$ RNA substrate (see Supplementary Figure S2E). (E) Helicase assay at substrate concentrations suitable for HTS. A time course of Cy3 signal was recorded using the indicated FH-nsp13 concentrations, $100 \mu \mathrm{M}$ ATP and $200 \mathrm{nM}$ DNA substrate. 


\section{Chemical library screen design and results}

We performed a HTS to identify inhibitors of SARS-CoV-2 nsp13 helicase activity using a custom chemical library containing over 5000 compounds. The compounds were dispensed into 384-well plates between columns 3 and 22. Wells in columns 2 and 23 on each plate served as solvent controls containing only DMSO (Supplementary Figure S3A). Nsp13 was incubated with compounds for $10 \mathrm{~min}$, then the substrates were dispensed to start the reaction (Figure 3A). The screen was performed at two compound concentrations, 1.25 and $6.25 \mu \mathrm{M}$. We observed that, on the day of the screen, the reaction was complete by $10 \mathrm{~min}$ (Supplementary Figure $\mathrm{S} 3 \mathrm{~B}$ ). The time required to dispense substrates to all the wells within a plate to start the reaction was $\sim 10 \mathrm{~s}$, while the time required to read all wells was $\sim 75 \mathrm{~s}$ (Supplementary Figure S3C,D). We applied a positional correction to the calculation of the initial velocity of reactions for each plate to compensate for this time delay, which improved positional variation in the dataset (Figure 3B,C). A total of 339 compounds showed $>20 \%$ reduction in corrected initial velocity or showed $>10 \%$ reduction in endpoint signals at either $1.25 \mu \mathrm{M}$ or $6.25 \mu \mathrm{M}$ compound concentration. Some data variation persisted in the corrected dataset, so we decided to manually inspect the kinetic curves of each hit compound in relation to the surrounding wells on the plate (example in Figure 3D). After manual inspection, 142 of the 339 compounds showed a clear effect in HTS reactions and were selected as primary hits. To find specific nsp13 inhibitors, we initially selected 35 of the primary hits that displayed $>30 \%$ reduction in corrected initial velocity for subsequent validation experiments (Figure 3E).

\section{Characterization of HTS hits}

In a first validation experiment, we tested the compounds using the same assay conditions as in the HTS and determined the compound concentration at which half-maximal nsp13 inhibition $\left(\mathrm{IC}_{50}\right)$ was observed. We found that 27 of the 33 tested compounds showed nsp13 inhibition with apparent $\mathrm{IC}_{50}$ values $<30 \mu \mathrm{M}$ (Supplementary Figure S4 and Table 1, second column). We then characterized the hits under more physiological conditions where the DNA substrate was replaced by its RNA counterpart, and the ATP concentration was increased from $100 \mu \mathrm{M}$ to $2 \mathrm{mM}$. Non-specific inhibition of enzymes due to colloidal aggregation of compounds is the most common source of false positives in high-throughput inhibitor screens [32-35]. The presence of non-ionic detergents can reduce colloid formation, which can lead to a right-shift of dose-response curves for many aggregation-prone compounds [36]. To uncover potential aggregators, we added 0.02\% Tween-20 to the reaction. Surprisingly, under these conditions only 5 out of 27 compounds still inhibited nsp13 and showed similar IC $_{50}$ values as in the first validation experiment (Supplementary Figure S5 and Table 1, third column). The remaining 22 compounds lost the strong inhibition shown in the first experiment, as indicated by the increase in their $\mathrm{IC}_{50}$ values (Table 1 , compare second column versus third column).

To test directly if some of our compounds could inhibit nsp13 activity via a detergent-sensitive aggregation mechanism [33,36], we tested 15 selected compounds in the presence or absence of Tween-20 with otherwise identical assay conditions (Supplementary Figure S6). The presence of Tween-20 reduced the inhibition of 13 of the 15 tested compounds, causing an $\mathrm{IC}_{50}$ shift greater than 4-fold (Supplementary Figure S6 and Table 1, fourth column), suggesting the nsp13 inhibition shown by these drugs in HTS and in the first validation experiment could be due to an aggregation effect. Colloidal aggregators absorb and inhibit enzymes without specificity $[32,34]$. Potential aggregators can be further confirmed by counter-screening against other enzymes [34]. Hence, we tested whether these compounds could inhibit the SARS-CoV-2 RdRp using a FRET-based assay developed in an accompanying manuscript (Bertolin et al.). Compounds with mild detergent sensitivity that still showed moderate to weak nsp13 inhibition in the presence of detergent, also inhibited RdRp in a similar fashion (e.g. Avasimibe, Supplementary Figure S7 and Supplementary Table S1). On the other hand, compounds that no longer inhibited nsp13 in the presence of detergents did not inhibit RdRp (e.g. A-385358, Supplementary Figure S7 and Supplementary Table S1). All together, these results suggest that many of the compounds identified in the nsp13 HTS were aggregation-based inhibitors. These findings are consistent with Aggregator Advisor, an open-access tool that advises on the likelihood of colloidal aggregation based on criteria including lipophilicity $(\log \mathrm{P}>3.5)$ and a structural similarity index $(>85 \%$ similarity compared with reported aggregators) [37]. We analysed the selected hits using this method and, not surprisingly, 21 out of 22 detergent-sensitive compounds showed $\log \mathrm{P}>3.5$ (Supplementary Table S2).

After this first round of analysis, we re-examined our primary hit list, and selected another 12 hit compounds with a $\log \mathrm{P}<3.6$ and with no significant similarity to known aggregators (Supplementary Table S3 


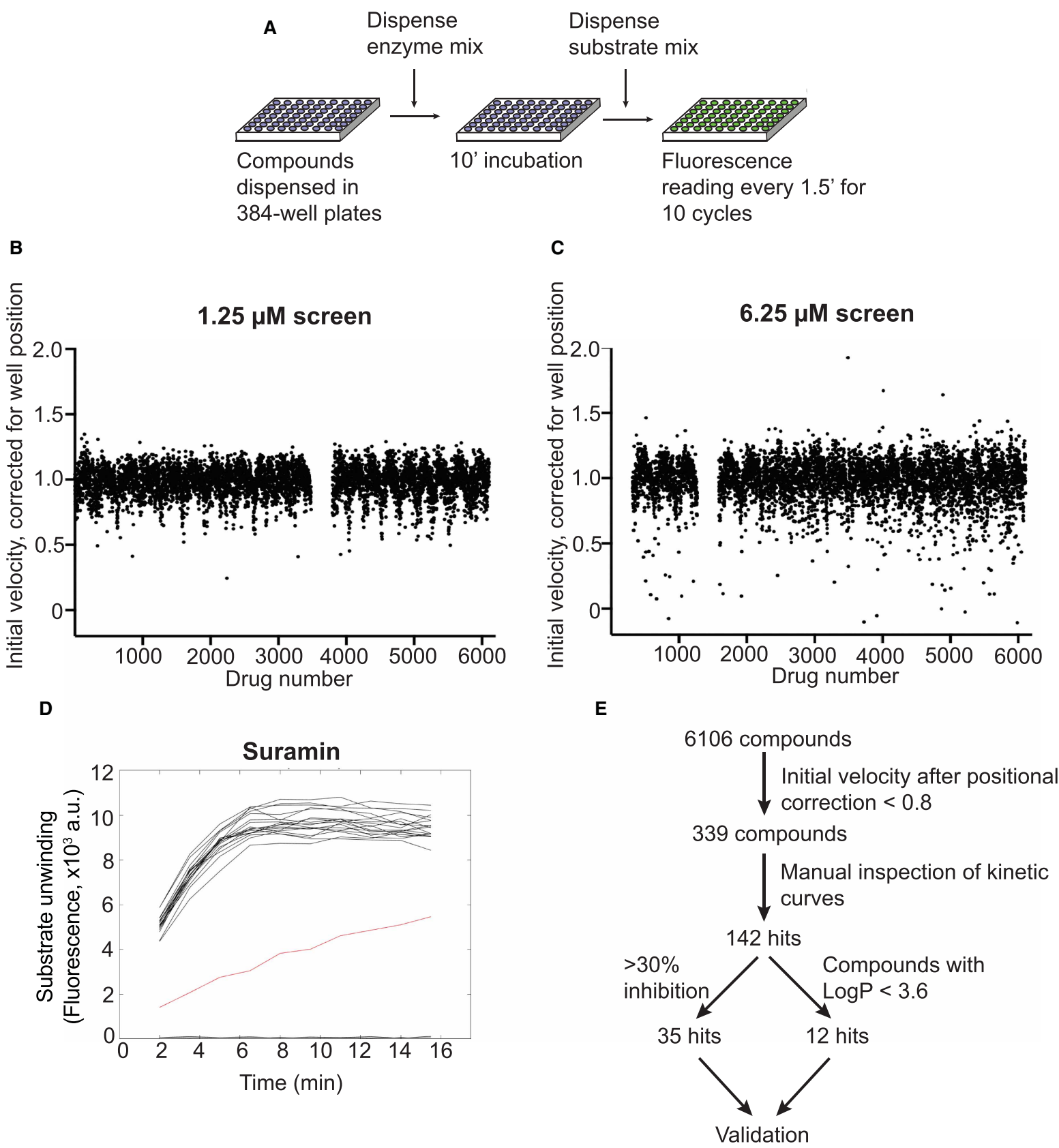

Figure 3. High-throughput screening for inhibitors of SARS-CoV-2 nsp13 helicase.

(A) Logistics of the HTS. A custom compound library was screened in 384-well plate format for inhibitors of nsp13 using the FRET-based helicase assay. A nsp13 solution was dispensed into compound-containing plates. After 10 min, reactions were started by addition of a substrate solution and fluorescence readings were taken in $90 \mathrm{~s}$ intervals. (B,C) Results of the screens performed at $1.25 \mu \mathrm{M}(\mathbf{B})$ and $6.25 \mu \mathrm{M}(\mathbf{C})$ compound concentration. Initial reaction velocity was corrected for well-position and plotted against compound number. (D) Kinetic curves of compounds that showed at least $20 \%$ reduction in corrected velocity were inspected manually. As example, time-course data for the compound suramin in the $6.25 \mu \mathrm{M}$ screen is shown (red curve, data from 20 surrounding wells in black). (E) Summary of HTS results. The process of hit selection for further validation is shown.

and Figure 3E) [37]. We also tested two published nsp13 inhibitors, SSYA10-001 [38,39] and myricetin [40]. We determined the $\mathrm{IC}_{50}$ values of all these compounds in the presence or absence of Tween-20 (Table 2 and Supplementary Figure S8). Eight of them did not show clear nsp13 inhibition in any condition. Hypocrellin A, 
Table 1. Inhibitory activity and detergent sensitivity of 35 identified compounds against SARS-CoV-2 nsp13

\begin{tabular}{|c|c|c|c|c|}
\hline \multirow[b]{2}{*}{ Compound name } & \multicolumn{4}{|l|}{$\mathrm{IC}_{50}(\mu \mathrm{M})$} \\
\hline & $\begin{array}{l}\text { No } \\
\text { detergent }\end{array}$ & $\begin{array}{l}+0.02 \% \\
\text { Tween-20 }\end{array}$ & $\begin{array}{l}0.02 \% \text { Tween-20 } \\
-/+\end{array}$ & $\begin{array}{l}\text { Data } \\
\text { figure }\end{array}$ \\
\hline NF 023 & 1.1 & 0.92 & $0.67 / 0.64$ & S4,S5,S6 \\
\hline Suramin & - & - & $0.74 / 1.6$ & S6 \\
\hline PPNDS & 2.0 & 1.6 & - & S4,S5 \\
\hline $\begin{array}{l}\text { PDK1/Akt/FIt Dual Pathway } \\
\text { Inhibitor }\end{array}$ & 1.1 & 0.90 & - & S4,S5 \\
\hline Evans Blue & 1.2 & 1.9 & - & S4,S5 \\
\hline Diphenyl Blue & 5.6 & 4.7 & - & S4,S5 \\
\hline Adapalene & 3.7 & 9.9 & $1.3 / 5.5$ & S4,S5,S6 \\
\hline Idasanutlin & - & - & $2.3 / 11$ & S6 \\
\hline TCID & 8.1 & 24 & $1.9 / 15$ & S4,S5,S6 \\
\hline Avasimibe & 4.0 & 13 & $1.3 / 17$ & S4,S5,S6 \\
\hline GW7647 & 5.9 & 27 & $2.3 / 25$ & S4,S5,S6 \\
\hline Gossypol & 1.9 & 30 & $1.3 / 31$ & S4,S5,S6 \\
\hline Linoleic acid & 11 & 38 & $4.3 / 36$ & S4,S5,S6 \\
\hline Cintirorgon & 2.3 & 38 & $2.1 / 41$ & S4,S5,S6 \\
\hline Zafirlukast & 3.6 & 53 & $1.5 / 50$ & S4,S5,S6 \\
\hline Eicosapentaenoic acid & 14 & 69 & - & S4,S5 \\
\hline Shikonin & 14 & 83 & $1.4 / 78$ & S4,S5,S6 \\
\hline Adomeglivant & 5.3 & 103 & - & S4,S5 \\
\hline TW-37 & 2.8 & 109 & - & S4,S5 \\
\hline Oleic acid & 6.8 & 58 & $14 / 117$ & S4,S5,S6 \\
\hline CARM1-IN-1 & 4.2 & 126 & - & S4,S5 \\
\hline Linifanib/ABT-869 & 26 & 230 & - & S4,S5 \\
\hline Navitoclax & 1.2 & $>250$ & $0.74 />250$ & S4,S5,S6 \\
\hline ABT-737 & 1.2 & $>250$ & - & S4,S5 \\
\hline RO8994 & 2.9 & $>250$ & - & S4,S5 \\
\hline A-385358 & 3.3 & $>250$ & - & S4,S5 \\
\hline Fenretinide & 9.1 & $>250$ & $7.3 />250$ & S4,S5,S6 \\
\hline Elaidic acid & 8.6 & $>250$ & - & S4,S5 \\
\hline Venetoclax/ABT-199 & 25 & $>250$ & - & S4,S5 \\
\hline Ceftiofur $\mathrm{HCl}$ & $>250$ & $>250$ & - & S4,S5 \\
\hline Leucovorin Calcium & $>250$ & $>250$ & - & S4,S5 \\
\hline SB-366791 & $>250$ & $>250$ & - & S4,S5 \\
\hline Mitoxantrone & Quenching & Quenching & - & S4,S5 \\
\hline 6-Hydroxy-DL-DOPA & Quenching & Quenching & - & S4,S5 \\
\hline Doxorubicin & Artifact & Artifact & - & S4,S5 \\
\hline
\end{tabular}


Table 2. Inhibitory activity against SARS-CoV-2 nsp13 and detergent sensitivity of 12 HTS hits selected in the second validation round and 2 control compounds

\begin{tabular}{|c|c|c|c|c|}
\hline \multirow[b]{2}{*}{ Compound name } & \multicolumn{4}{|l|}{$I_{50}(\mu \mathrm{M})$} \\
\hline & No detergent ${ }^{1}$ & $+0.02 \%$ Tween-20 1 & $+0.01 \%$ Triton $\mathrm{X}-100^{2}$ & Data figure \\
\hline FPA 124 & 8.5 & 8.4 & 8.9 & S8,S9 \\
\hline Hypocrellin A & 12 & $>250$ & - & S8 \\
\hline TAK875 & 19 & 72 & - & S8 \\
\hline Elvitegravir & 22 & $>250$ & - & S8 \\
\hline NDP-BVU-972 & 75 & $>250$ & - & S8 \\
\hline Eplerenone & $>250$ & No inhibition & - & S8 \\
\hline Fluocinolone Acetonide & $>250$ & No inhibition & - & S8 \\
\hline Omapatrilat & $>250$ & No inhibition & - & S8 \\
\hline ADL5859 & $>250$ & No inhibition & - & S8 \\
\hline Nedocromil & No inhibition & No inhibition & - & S8 \\
\hline Lifitegrast & No inhibition & No inhibition & - & S8 \\
\hline SKF 89145 & No inhibition & No inhibition & - & S8 \\
\hline Suramin $^{3}$ & 0.94 & 1.1 & 1.6 & S8,S9 \\
\hline Zafirlukast $^{3}$ & 6.6 & 55 & 22 & S8,S9 \\
\hline SSYA10-00 $1^{4}$ & 7.5 & 28 & 21 & S8,S9 \\
\hline Myricetin ${ }^{5}$ & 24 & 125 & - & S8 \\
\hline \multicolumn{5}{|c|}{$\begin{array}{l}{ }^{1} \text { Experimental conditions: RNA, } 0.1 \mathrm{mM} \text { ATP. See Supplementary Figure S8. } \\
{ }^{2} \text { Experimental conditions: RNA, } 0.1 \mathrm{mM} \text { ATP. See Supplementary Figure S9. } \\
{ }^{3} \text { Suramin and zafirlukast, compounds characterized in Table 1, were included for comparison purposes. } \\
{ }^{4} \text { Literature compound. See [38]. } \\
{ }^{5} \text { Literature compound. See [40]. }\end{array}$} \\
\hline
\end{tabular}

TAK875 and elvitegravir together with the published nsp13 inhibitor myricetin showed clear inhibition only in the absence of detergent (Table 2 and Supplementary Figure S8). The other published nsp13 inhibitor SSYA10-001 presented moderate sensitivity to detergent. FPA-124 was the only compound that inhibited nsp13 with no detergent sensitivity in this test (Table 2 and Supplementary Figures S8 and S9).

After all the above analyses, we found seven compounds that inhibited nsp13 with no detergent sensitivity (PDK1/Akt/Flt Dual Pathway Inhibitor, suramin and suramin-related compounds, and FPA-124, Supplementary Figure S10). PDK1/Akt/Flt Dual Pathway Inhibitor showed promiscuous inhibition in several other screens, including the RdRp screen, nsp3 papain-like protease screen, nsp5 main protease screen and nsp15 endonuclease screen [41]. Therefore, it was excluded from further analysis. Suramin and suramin-related compounds (NF 023, PPNDS, Evans Blue and Diphenyl Blue) are heavily negatively charged molecules and may inhibit nucleic acid-binding proteins by binding to positively charged protein regions [42-46]. They were also identified as hits in the RdRp screen (Bertolin et al. [47]) but not in other parallel screens, consistent with the ability of these polyanionic compounds to strongly inhibit certain nucleic acid-binding proteins [43,48-50]. Notably, a kinase inhibitor, FPA-124, inhibited nsp13 with a micromolar $\mathrm{IC}_{50}$ of $\sim 9 \mu \mathrm{M}$, and its $\mathrm{IC}_{50}$ value was not affected by the addition of the non-ionic detergents Tween-20 or Triton X-100 (Supplementary Figures S8 and S9), suggesting its nsp13 inhibition was unlikely to be due to aggregation. Moreover, FPA-124 did not score as a hit in the RdRp screen nor parallel screens against other SARS-CoV-2 enzymes [41,47,51-54], indicating its inhibitory activity is likely target specific. Examples of the observed $\mathrm{IC}_{50}$ curves are shown in Figure 4. Suramin, NF 023 and FPA-124 are compounds whose enzymatic inhibition is largely insensitive to detergent addition (Figure 4A,C). On the other hand, navitoclax and linoleic acid are examples of compounds with high $\log P$ values and strong sensitivity to detergents suggesting that their inhibitory effect could be attributed to colloidal aggregation occurring at certain micromolar concentrations (Figure 4D,E). 

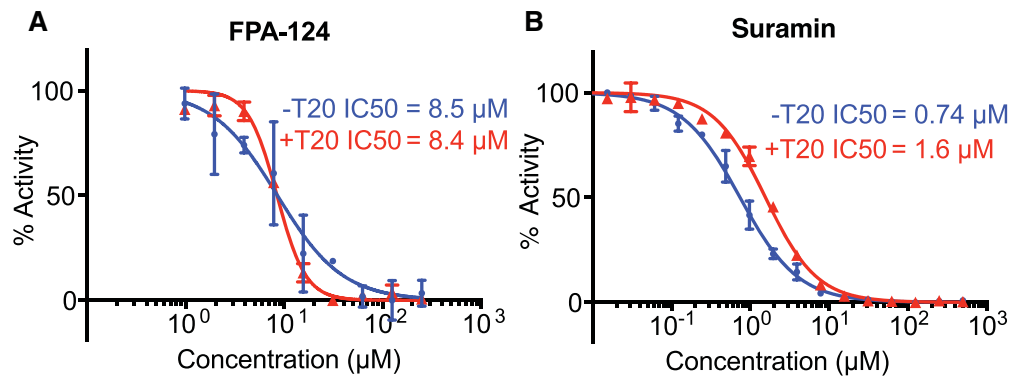

E
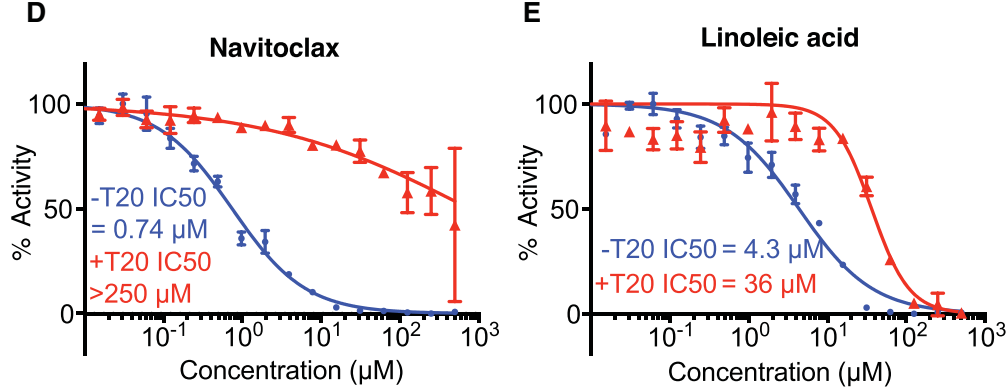

$\mathbf{F}$
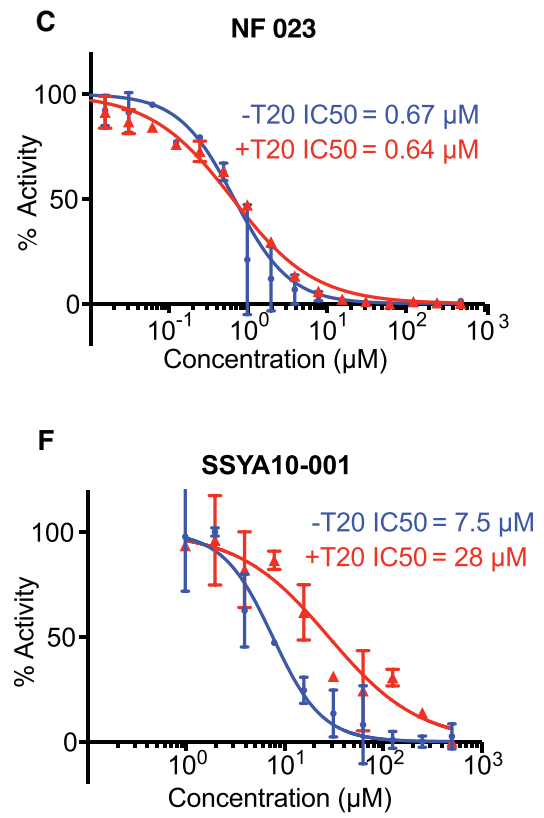

G

Gel-based helicase assay
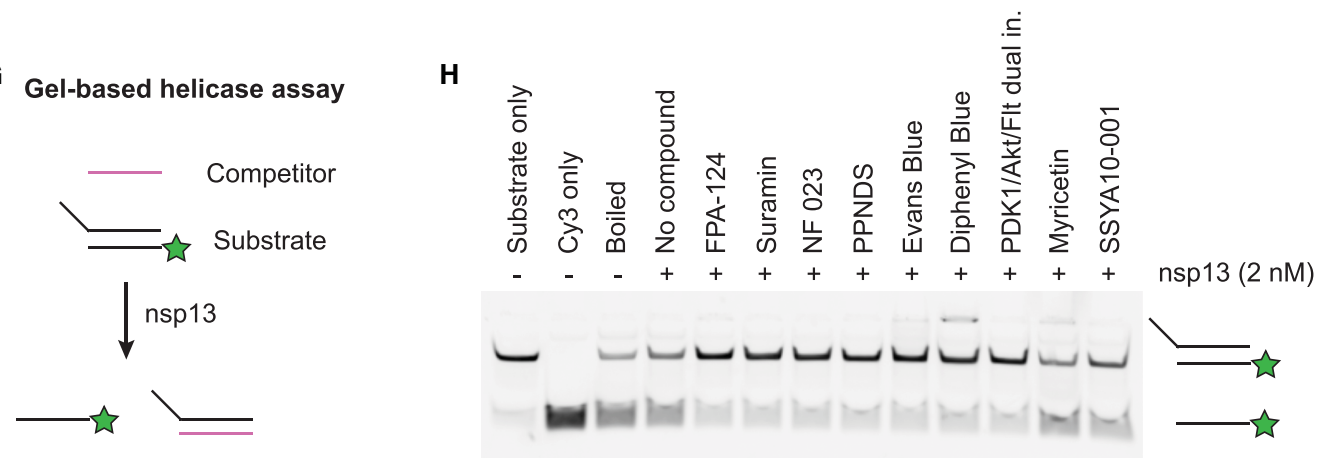

Figure 4. In vitro validation of selected compounds identified as nsp13 inhibitors.

(A-F) Concentration-response curves of selected compounds determined using the FRET-based nsp13 helicase assay. The results shown here are part of the larger experiment shown in Supplementary Figure S6 (for B-E) or S7 (for A, F). The experiment was performed in the presence (+T20) or absence $(-\mathrm{T} 20)$ of $0.02 \%$ Tween-20. FPA-124 (A), Suramin (B) and NF 023 (C) showed little or no detergent sensitivity, whereas Navitoclax (D), Linoleic acid (E) and SSYA10-001 (F) showed an increase in $\mathrm{IC}_{50}$ when Tween-20 was included. $\mathrm{IC}_{50}$ values were calculated with Prism software. (G) Schematic diagram illustrating the gel-based nsp13 helicase assay. A nucleic acid substrate with a 5 ' overhang is generated by annealing a Cy3-labelled oligonucleotide (Cy3 strand) with a longer unlabelled oligonucleotide. A 10-fold excess of competitor oligonucleotide is used to capture the longer strand after nsp13 unwinds the substrate. (H) Validation of selected compounds in a gel-based nsp13 helicase assay visualizing inhibition of duplex unwinding. Compounds were incubated with $2 \mathrm{nM}$ FH-nsp13 at $15 \mu \mathrm{M}$ compound concentration for 10 min before reactions were started by addition of $2 \mathrm{mM}$ ATP and $50 \mathrm{nM}$ RNA substrate. After 5 min reaction products were analysed by native PAGE and visualization of Cy3 fluorescence. Controls: RNA substrate (Substrate only), Cy3 strand only (Cy3 only), RNA substrate after 5 min incubation at $95^{\circ} \mathrm{C}$ (Boiled).

We also tested these compounds in a gel-based nsp13 helicase assay (Figure 4G,H). We used an RNA substrate consisting of a Cy3 strand and an unlabelled complementary strand with a $5^{\prime}$ overhang. A competitor strand was included to capture the unlabelled strand. Reaction products were then separated by native PAGE and detected by $\mathrm{Cy} 3$ fluorescence. We tested the identified detergent-insensitive compounds (FPA-124, suramin, NF 023, PPNDS, Evans Blue, Diphenyl Blue) together with the two published SARS-CoV-1 nsp13 
inhibitors, myricetin and SSYA10-001, at a compound concentration of $15 \mu \mathrm{M}$ in the presence of $0.01 \%$ Triton $\mathrm{X}$-100. All 6 identified compounds clearly reduced the generation of single-stranded Cy3 strand, confirming that the compounds inhibited helicase activity (Figure $4 \mathrm{H}$ ), while myricetin and SSYA10-001 inhibited nsp13 with less efficiency under these conditions.

\section{Viral inhibition assays}

We next evaluated the potential antiviral activity of the compounds against SARS-CoV-2 in Vero E6 cells. Our experiments thus far identified six compounds that inhibited nsp13 in biochemical assays. Of these, suramin, PPNDS, NF 023, Evans Blue and Diphenyl Blue are structurally related compounds containing at least one polysulfonated naphthyl group, which is believed to be the critical pharmacophore $[42,43]$. Suramin is the prototypical naphthalene polysulfonated compound and the most studied drug of this group, so we tested suramin in our cell-based experiments. The other validated inhibitor was FPA-124, which is a cell-permeable selective AKT inhibitor [55]. We also included the two published SARS-CoV-1 nsp13 inhibitors SSYA10-001 and myricetin [38-40]. To test an effect on viral replication, the compounds were added to Vero E6 cells, and then cells were infected with SARS-CoV-2 at a multiplicity of infection of 0.5 . After $22 \mathrm{~h}$ cells were fixed and analysed by immunofluorescence (Figure 5A). Immunofluorescent detection of SARS-CoV-2 nucleocapsid (N) protein was used as a read out for viral replication in cell culture (see Material and methods). The compounds were tested over a range of concentrations, and the half-maximal effective concentration $\left(\mathrm{EC}_{50}\right)$ for each compound was calculated (Figure 5B,C). Suramin and FPA-124 showed viral inhibition with EC $_{50}$ values of $9.9 \mu \mathrm{M}$ and $14 \mu \mathrm{M}$, respectively, while the published nsp13 inhibitors, myricetin and SSYA10-001, presented a weaker viral inhibition potency $\left(\mathrm{EC}_{50}=32 \mu \mathrm{M}\right.$ and $81 \mu \mathrm{M}$, respectively). Of these four tested compounds, only FPA-124 showed considerable inhibition of cellular growth at high concentrations (100-300 $\mu \mathrm{M})$, perhaps due to inhibition of AKT kinase (Supplementary Figure S11A) [55].

Combining two antiviral drugs with different viral or cellular targets can result in improved outcomes compared with antiviral monotherapy [56]. Therefore, we decided to investigate the potential synergy between nsp13 inhibitors and the RdRp inhibitor remdesivir [10-12]. Following the same infection protocol described in Figure 5A, the compounds were again tested over a range of concentrations in the presence of $1 \mu \mathrm{M}$ remdesivir. At this concentration, remdesivir alone inhibited viral infection by less than $20 \%$. None of the evaluated nsp13 inhibitors showed significant synergy with remdesivir under these assay conditions (Supplementary Figure S11B).

\section{Discussion}

The SARS-CoV-2 protein nsp13 possesses helicase activity and is essential for viral replication and proliferation [25-27,57]. Moreover, nsp13 is the most conserved non-structural protein within the coronavirus family, making it a very promising target for the development of pan-coronavirus antivirals [23]. In this study, we developed a robust FRET-based helicase assay and used it for high-throughput inhibitor screening testing over 5000 previously characterized pharmaceuticals. We report the identification of FPA-124 and suramin-like compounds as novel inhibitors of nsp13. We performed comparative analyses between the two most promising inhibitors reported in this work (FPA-124 and suramin) and two SARS-CoV-1 nsp13 inhibitors described in the literature (myricetin [40] and SSYA10-001 [38,39]). We showed that FPA-124 and suramin have lower IC $_{50}$ against nsp13 in vitro and lower antiviral $\mathrm{EC}_{50}$ in cell-based assays than the two published compounds.

Colloid formation by aggregation-prone compounds is one of the main sources of false positives in drug discovery [34,35]. Adding non-ionic detergents can reduce the colloid formation and thus advise on the specificity of HTS hits [32,36]. All subsequent screens in this series of papers used detergents in the primary screens. We performed the SARS-CoV-2 nsp13 HTS in the absence of detergents and obtained 142 primary hits. We then tested a selection of 47 hits with different non-ionic detergents in validation assays. Seven of those tested showed no or only mild changes in $\mathrm{IC}_{50}$ values after detergent addition, including FPA-124 and suramin-like compounds (Supplementary Figures S6-S9). On the other hand, other hits from the primary screen had a significant decrease in potency when assayed in detergent-containing buffers (Supplementary Figures S8 and S9). We then tested a selection of the detergent-sensitive hits against a different enzyme, the SARS-CoV-2 RdRp. We found they had a similar inhibitory effect on both nsp13 and RdRp further suggesting their mode of action could involve non-specific protein capture by colloid formation. Myricetin and SSYA10-001, two previously reported SARS-CoV-1 nsp13 inhibitors, showed reduced potency when assayed in our detergent-containing buffers in the FRET-based assay. Indeed, myricetin has been reported to have an aggregator-like behaviour 
A

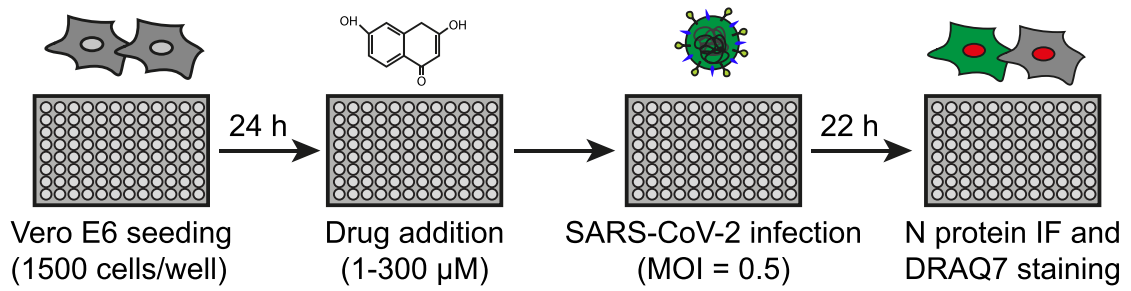

B

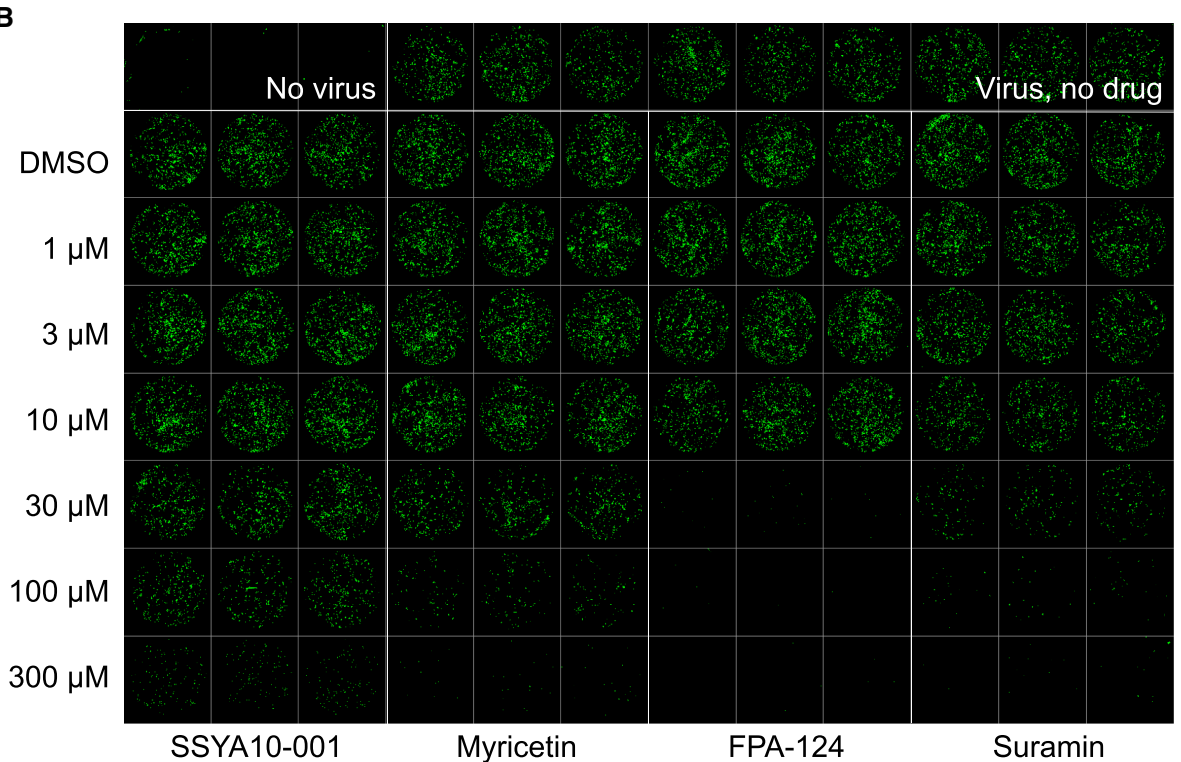

C
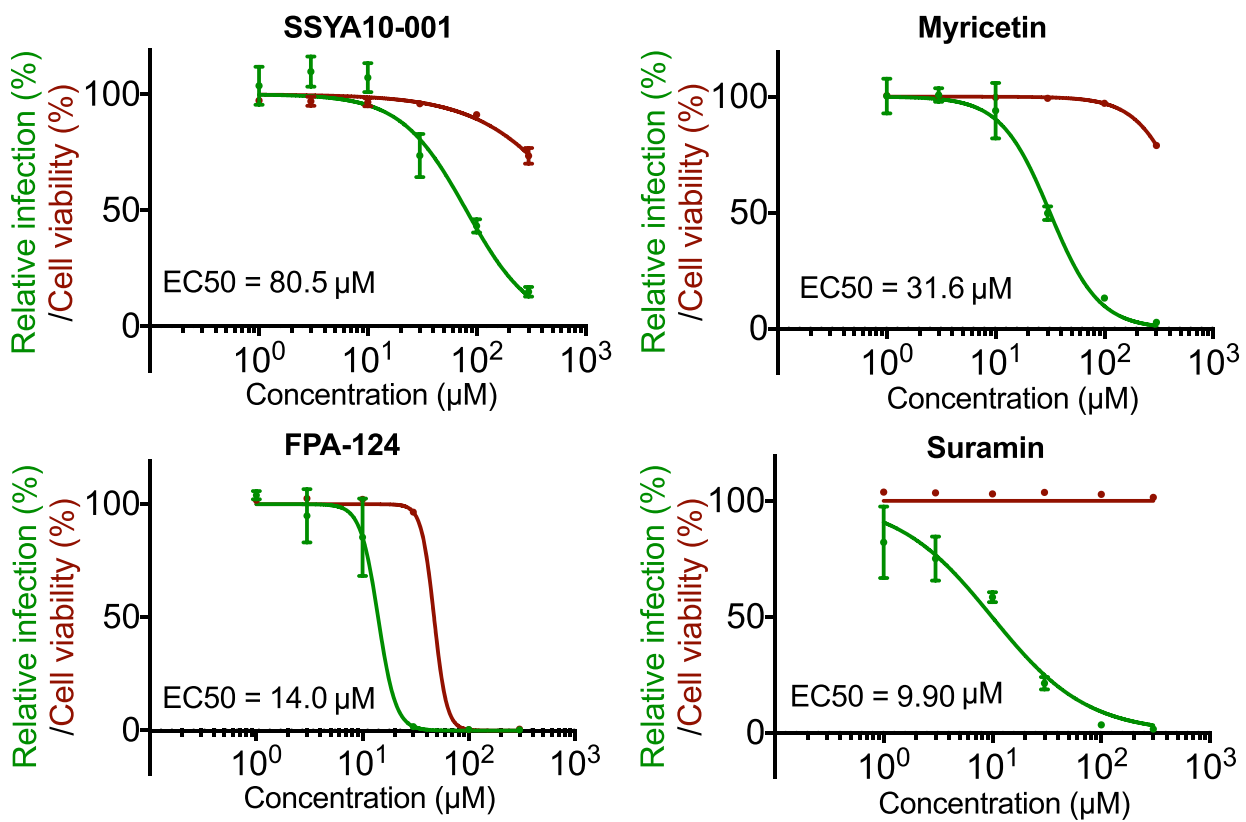

Figure 5. Antiviral activity of selected compounds against SARS-CoV-2 in cell culture.

Part 1 of 2

(A) Schematics of the viral infection inhibition protocol. In brief, Vero E6 cells were seeded in a 96-well format and after $24 \mathrm{~h}$ were treated with selected compounds at defined concentrations. The cultures were infected with SARS-CoV-2 at a MOI of 0.5 PFU/cell. Twenty-two hours after infection, cells were fixed and analysed by immunofluorescence staining and imaging. (B) Confocal microscope images of viral N protein staining (green) show anti-SARS-CoV-2 activities of SSYA10-001, myricetin, suramin and FPA-124 at indicated concentrations. The corresponding DRAQ7-stained cell nuclei images are shown in 

measured as the area of viral plaques stained for $\mathrm{N}$ protein (green lines) and cell viability as the area of cells stained for DRAQ7 (red lines). Data are plotted as percentage compared with DMSO only control wells (100\%). Values represent mean and standard deviation (SD) of 3 replicates. Areas were determined using FIJI software and $\mathrm{EC}_{50}$ values were calculated with Prism software.

[58-60] and to form colloidal aggregates detectable by dynamic light scattering [61], raising concerns about the specificity of its reported SARS-CoV-1 nsp13 inhibition [40]. Nonetheless, detergent sensitivity does not completely rule out a genuine inhibitory effect [37]. Sometimes this promiscuous activity occurs solely at different concentrations than specific binding-based inhibition. Therefore, some of the compounds that presented a detergent-dependent decrease in inhibition reported in this work may still have genuine inhibitory activity against nsp13 at certain concentrations.

FPA-124 is a cell-permeable Akt inhibitor that induces apoptosis in multiple cancer cell lines [55]. We showed that this compound has an $\mathrm{IC}_{50}$ of $\sim 9 \mu \mathrm{M}$ and is not detergent-sensitive in in vitro assays. FPA-124 was not a hit in any of the other screens in this series [41,47,51-54] providing further evidence for its nsp13 specificity. When tested in cell-based assays, FPA-124 inhibited viral growth at an $\mathrm{EC}_{50}$ of $\sim 14 \mu \mathrm{M}$, below its observed cytotoxicity $(>100 \mu \mathrm{M})$. Its cytotoxicity is probably caused by inhibition of this compound's original cellular target Akt as Akt signalling is shown to be important for cell survival (Figure 5B,C and Supplementary Figure S11A) [55]. Interestingly, PI3K/Akt/mTOR signalling inhibition has been demonstrated to suppress SARS-CoV-2 replication in mammalian cells $[62,63]$. From the current study, we cannot elucidate whether FPA-124 inhibits viral growth by inhibiting nsp13 activity, modulating Akt signalling or a combination of both mechanisms.

Suramin, originally synthesized by Bayer in 1916, is a clinically approved drug mainly used to treat river blindness and sleeping sickness $[43,64]$. We show that suramin and several of its structurally similar compounds are novel inhibitors of SARS-CoV-2 nsp13. Suramin inhibited nsp13 in vitro with an $\mathrm{IC}_{50}$ of $\sim 1 \mu \mathrm{M}$ and inhibited viral growth in cell-based assays with an $\mathrm{EC}_{50}$ of $\sim 10 \mu \mathrm{M}$. A wide range of antiviral effects have been reported for suramin, as it inhibits Zika virus, dengue virus, chikungunya virus, HIV, hepatitis $\mathrm{C}$ virus, herpes simplex type-1 virus and recently SARS-CoV-2 [43,65]. Suramin seems to inhibit multiple steps in viral infection and replication: it interferes with virus-receptor interaction and hence viral-host cell binding and uptake [66,67], it interferes with viral helicase activities ([48] and this work) and it interferes with viral RNA polymerase activity $[49,68]$. Suramin is a large symmetrical molecule carrying two polysulfonated naphthyl urea groups containing six negative charges at physiological $\mathrm{pH}$ and therefore, the basis for its many targets is likely to be its ability to strongly bind positively charged regions in proteins such as polymerases $[44,46]$. Indeed, we show that suramin and related compounds also inhibited the SARS-CoV-2 RdRp with micromolar $\mathrm{IC}_{50} \mathrm{~s}$ without detergent sensitivity. The polyanionic nature of suramin also confers low cell membrane permeability. However, suramin can be taken up by endocytosis and the uptake rate can be enhanced by liposomal delivery [69].

We validated suramin, suramin-like compounds and FPA-124 as nsp13 inhibitors that could be subjected to careful structural optimization to generate clinically more useful compounds in the hope of increasing antiviral potency and reducing cytotoxicity. Co-structures of nsp13 and these small-molecule inhibitors could highly benefit these optimization processes. The viral RNA polymerase inhibitor, remdesivir, is currently the only FDA-approved small-molecule antiviral for the treatment of COVID-19 patients [10,70]. However, it is far from being a silver bullet as it has been shown to be only modestly effective in treating very sick patients [10,70]. Thus, combining remdesivir with a mechanistically distinct drug (e.g. drugs that target other SARS-CoV-2 enzymatic activities) may improve antiviral efficacy and reduce the likelihood of emerging drug resistance [71]. Nonetheless, our experiments in Vero cells showed no synergistic inhibition on viral replication when combining remdesivir and our nsp13 inhibitors. It would be of interest to test the potential synergy between different nsp13 inhibitors and also between nsp13 inhibitors and SARS-CoV-2 enzyme inhibitors identified in parallel screens $[41,47,51-54]$ in the future. Recent studies on host-virus interactions suggest that SARS-CoV-2 nsp13 may also be implicated in immune suppression as it targets several host proteins involved in innate immune signalling pathways such as the interferon pathway and NF- $\mathrm{BB}$ pathway [72]. Vero E6 cell 
experiments are useful tools for studying viral replication, but it would be interesting to test our nsp13 inhibitors in other cell lines that have intact innate immune responses in the future [73].

In conclusion, we have identified novel small-molecule inhibitors of SARS-CoV-2 nsp13 helicase. We provide evidence that suramin and FPA-124 can be considered as leads that deserve further evaluation, as both compounds were found to inhibit nsp13 in vitro and exhibit antiviral activity against SARS-CoV-2 in a relevant cell culture model.

\section{Materials and methods Protein expression and purification}

FH-nsp13 and GST-nsp13 were expressed in baculovirus-infected insect cells. The coding sequence of SARS-CoV-2 nsp13 (NCBI reference sequence NC_045512.2) was codon-optimised for Spodoptera frugiperda and synthesized (GeneArt, Thermo Fisher Scientific). Nsp13 was subcloned into the biGBac vector pLIB [74] either to contain an N-terminal $3 x^{x}$ Flag-His ${ }_{6}$ tag (sequence: MDYKDHDGDYKDHDIDYKDDDDKGSHHHH HHSAVLQ-nsp13) (pLIB_3xFlag-His6-nsp13, Addgene ID: 169189) or to contain an N-terminal GST fusion derived from pGEX-4T-1 (pLIB_GST-nsp13, Addgene ID: 169190). Baculoviruses were generated and amplified in Sf9 insect cells (Thermo Fisher Scientific) using the EMBacY baculoviral genome [75]. For protein expression, Sf9 cells were infected with baculovirus and collected $48 \mathrm{~h}$ post infection, flash frozen and stored at $-70^{\circ} \mathrm{C}$. FH-nsp13 and GST-nsp13 were affinity purified from insect cell lysates using anti-FLAG M2 Affinity Gel (Sigma-Aldrich) or Glutathione Sepharose 4 Fast Flow resin (GE Healthcare) following the instructions provided by the manufacturer with appropriate modifications. All steps were performed at $4^{\circ} \mathrm{C}$. Cell pellets were lysed by Dounce homogenization using a loose-fitting homogenizer pestle in $50 \mathrm{mM}$ HEPES pH 7.4, $200 \mathrm{mM} \mathrm{NaCl}, 10 \%$ Glycerol, $1 \mathrm{mM}$ DTT and the following protease inhibitors: $1 \mathrm{mM}$ PMSF, $0.2 \mathrm{mM}$ AEBSF, $1 \mu \mathrm{g} / \mathrm{ml}$ Aprotinin, $1 \mu \mathrm{M}$ pepstatin, $10 \mu \mathrm{M}$ leupeptin, $2 \mathrm{mM}$ Benzamidine, and $1 \times$ protease inhibitor cocktail (Complete Ultra Tablets, Roche). The lysate was clarified by centrifugation at $39000 \mathrm{~g}$ at $4^{\circ} \mathrm{C}$ for $60 \mathrm{~min}$. Anti-FLAG M2 resin was added to the FH-nsp13 supernatant and Glutathione Sepharose 4 Fast Flow resin was added to the GST-nsp13 supernatant, and gently rotated for $2 \mathrm{~h}$ at $4^{\circ} \mathrm{C}$. The resins were transferred into gravity-flow columns, washed with wash buffer $(50 \mathrm{mM}$ HEPES pH 7.4, $200 \mathrm{mM} \mathrm{NaCl}, 10 \%$ glycerol, $1 \mathrm{mM}$ DTT) and eluted with the respective elution buffer (wash buffer supplemented with $0.1 \mathrm{mg} / \mathrm{ml} 3 \times \mathrm{xFLAG}$ peptide or wash buffer supplemented with $10 \mathrm{mM}$ reduced glutathione). Both eluates were then fractionated by gel filtration on a Superdex-200 Increase 10/300GL column (GE Healthcare) in buffer containing $50 \mathrm{mM}$ Tris $\mathrm{pH} 8.0,200 \mathrm{mM} \mathrm{NaCl}, 1 \mathrm{mM}$ DTT and $10 \%$ glycerol. Fractions containing the desired protein were concentrated, flash frozen in liquid nitrogen and stored at $-80^{\circ} \mathrm{C}$.

\section{FRET-based nsp13 helicase assay}

A FRET-based fluorescence-quenching approach was designed to monitor nucleic acid strand separation catalyzed by nsp13. The assay uses a forked duplex DNA or RNA substrate (15-bp duplex with a 20-nt oligo-dT $5^{\prime}$ overhang). One strand contains a Cy3 fluorophore at the $5^{\prime}$ end (Cy3 strand, DNA or RNA) and the other strand a Black Hole Quencher-2 (BHQ-2, DNA) or an Iowa black RQ quencher (AbRQ, RNA) at the $3^{\prime}$ end (quencher strand). A DNA competitor strand that is complementary to the Cy3 strand prevents substrate re-annealing. HPLC-purified DNA and RNA oligonucleotides were purchased from Eurofins genomics and IDT, respectively, with the following sequences:

Cy3 strand DNA: 5'-Cy3-GGTAGTAATCCGCTC-3'

BHQ-2 strand DNA: $5^{\prime}$-TTTTTTTTTTTTTTTTTTTTGAGCGGATTACTACC-(BHQ-2)-3'

Cy3 strand RNA: $5^{\prime}$-Cy3-GGUAGUAAUCCGCUC- $3^{\prime}$

Iowa Black RQ strand RNA: $5^{\prime}$-UUUUUUUUUUUUUUUUUUUUGAGCGGAUUACUACC-(AbRQ)- $3^{\prime}$

Competitor strand DNA: $5^{\prime}$-GAGCGGATTACTACC-3'

The Cy3 strand and the quenching strand were annealed at $1: 1.1$ ratio at a concentration of $20 \mu \mathrm{M}: 22 \mu \mathrm{M}$, respectively, by heating the oligo mix to $75^{\circ} \mathrm{C}$ for $5 \mathrm{~min}$ and gradually cooling it down to $4^{\circ} \mathrm{C}$ over $50 \mathrm{~min}$. The competitor strand was added at 5 times the concentration of the duplex for inhibitor screens and validation assays. A reaction was typically started by adding $10 \mu \mathrm{l}$ of a $2 \times$ substrate solution containing a DNA or RNA substrate and ATP in reaction buffer (20 mM HEPES pH 7.6, $20 \mathrm{mM} \mathrm{NaCl}, 5 \mathrm{mM} \mathrm{MgCl}, 1 \mathrm{mM}$ DTT and $0.1 \mathrm{mg} / \mathrm{ml} \mathrm{BSA}$ ) to $10 \mu \mathrm{l}$ of a $2 \times$ enzyme solution containing nsp13 in reaction buffer. Upon unwinding of the duplex by nsp13, Cy3 is no longer quenched by BHQ-2 and thus able to fluoresce. The fluorescence signal was 
read at $550 \mathrm{~nm}$ (excitation) and $570 \mathrm{~nm}$ (emission) with $5 \mathrm{~nm}$ bandwidth using a Tecan Infinite M1000, or at $545 \mathrm{~nm}$ (excitation) and $575 \mathrm{~nm}$ (emission) with $10 \mathrm{~nm}$ bandwidth using a Tecan Spark microplate reader.

\section{Radiolabelled substrate-based nsp13 helicase assay}

The oligonucleotides used in the radiolabelled assays are the following:

Short strand DNA: 5'-GGTAGTAATCCGCTC-3'

$\mathbf{5}^{\prime}$ overhang strand DNA: $5^{\prime}$-TTTTTTTTTTTTTTTTTTTTGAGCGGATTACTACC- $3^{\prime}$

Short strand RNA: $5^{\prime}$-GGUAGUAAUCCGCUC- $3^{\prime}$

$5^{\prime}$ overhang strand RNA: $5^{\prime}$-UUUUUUUUUUUUUUUUUUUUGAGCGGAUUACUACC-3'

Competitor strand DNA: $5^{\prime}$-TTTTTTTTTTTTTTTTTTTTGAGCGGATTACTACC- $3^{\prime}$

DNA or RNA oligonucleotide containing the $5^{\prime}$ overhang $\left(5^{\prime}\right.$ overhang strand) was radiolabelled at the $5^{\prime}$ ends with $\left[\gamma_{-}{ }^{32} \mathrm{P}\right]$ ATP by T4 PNK. The unmodified DNA version of the $5^{\prime}$ overhang strand was used as the competitor strand. The unwinding reactions were carried out at room temperature in helicase buffer $(20 \mathrm{mM} \mathrm{HEPES} \mathrm{pH}$ 7.5, $20 \mathrm{mM} \mathrm{NaCl}, 5 \mathrm{mM} \mathrm{MgCl}, 100 \mu \mathrm{g} / \mathrm{ml} \mathrm{BSA}, 1 \mathrm{mM}$ DTT, RNase inhibitor Murine (NEB) 2 units/ $\mu \mathrm{l}$ ) containing $1 \mathrm{mM}$ ATP for $50 \mathrm{nM}$ DNA substrate or $2 \mathrm{mM}$ ATP for $100 \mathrm{nM}$ RNA substrate. The unwinding reactions were quenched at various times with a quench solution containing $50 \mathrm{mM}$ EDTA. The aliquots then were mixed with $5 \times$ loading buffer (TBE buffer, 15\% Ficoll, $1 \mu \mathrm{g} / \mathrm{ml}$ bromophenol blue, $1 \mu \mathrm{g} / \mathrm{ml}$ xylene cyanol FF). The products of the unwinding reactions were separated on a $20 \%$ native PAGE $(0.5 \times \mathrm{TBE})$. The gels were dried and then exposed to a Phospho-Imager screen overnight, imaged using Phospho-Imager software.

\section{Nsp13 high-throughput screening assay}

The screen was performed in 384-well Greiner black flat-bottom plates (Greiner 781076). A custom compound library containing over 5000 compounds assembled from commercial sources (Sigma, Selleck, Enzo, Tocris, Calbiochem, and Symansis) were distributed in 24 plates using an Echo 550 (Labcyte) across column 3-22; 2.5, or $12.5 \mathrm{nl}$ of a $10 \mathrm{mM}$ stock of the compounds dissolved in DMSO were arrayed and pre-dispensed into the assay plates using an Echo 550 (Labcyte), before being sealed and stored at $-80^{\circ} \mathrm{C}$ until screening day. All 384 wells on the plates contain $1 \mu \mathrm{l}$ DMSO. First, $10 \mu \mathrm{l} 2 \times \mathrm{Nsp} 13 \mathrm{mix}(6 \mathrm{nM}$ FH-nsp13) in HTS assay buffer (20 mM HEPES pH 7.6, $20 \mathrm{mM} \mathrm{NaCl}, 5 \mathrm{mM} \mathrm{MgCl} 2,1 \mathrm{mM} \mathrm{DTT}$ and $0.1 \mathrm{mg} / \mathrm{ml} \mathrm{BSA}$ ) was dispensed into columns 2-23 of the plates to incubate with the compounds for $10 \mathrm{~min}$ at room temperature. Then $10 \mu \mathrm{l} 2 \times$ substrate mix (200 $\mu$ M ATP, $360 \mathrm{nM}$ DNA substrate, $1800 \mathrm{nM}$ competitor) in HTS assay buffer was dispensed to start the enzymatic reaction. The plates were then spun briefly and transferred to a Tecan microplate reader to monitor changes in fluorescence signal in a kinetic mode. The fluorescence signal was first read at $2 \mathrm{~min}$ of reaction and then read every $1.5 \mathrm{~min}$ for 10 cycles. The screening for nsp13 inhibitors was done twice, one with a final compound concentration of $1.25 \mu \mathrm{M}$ and one with $6.25 \mu \mathrm{M}$.

\section{Data analysis}

The first fluorescence signal at $2 \mathrm{~min}$ after the reaction start in the screen was used as the initial velocity $\left(V_{0}\right)$ to compare nsp13 activity in different wells. MATLAB was used to process data. The initial velocity for each compound is first normalized against the DMSO controls in column 23 of each plate as following:

$$
\text { Normalized_ } V_{0}=\left[V_{0 \_} \text {of_compound }-\operatorname{mean}(\text { no_enzyme })\right] /\left[\text { mean }\left(V_{0} \_D M S O\right)-\text { mean (no_enzyme) }\right]
$$

Because there was a time delay in reading different wells by the microplate reader, reactions in wells that were read later progressed further than wells that were read earlier in each cycle, resulting in higher signals towards the end of a microplate. This positional variation is corrected as following:

For each plate, a linear regression of Normalized_ $V_{0}$ is fitted against well numbers of wells in between column 2 and column 23. A slope value $(S)$ and an intercept value $(I)$ from this linear regression were obtained and used to do the positional correction for the Nth well of a 384-well plate.

$$
\text { Corrected_ } V_{0}=\text { Normalised_ } V_{0} /(S * N+I)
$$

For endpoint analysis, fluorescent signals from $6.5 \mathrm{~min}, 8 \mathrm{~min}$ and $9.5 \mathrm{~min}$ were taken average when the enzymatic reaction had finished in the DMSO control wells. Compounds that gave more than $10 \%$ inhibition 
in endpoint analysis were considered hits and were collated with hits from initial velocity analysis. Plate 14 from the $1.25 \mu \mathrm{M}$ screen, plate 1 and 5 from $6.25 \mu \mathrm{M}$ screen were excluded from data analysis because of faulty handling of the plates. In total, there were 339 hits after the initial selection.

For preliminary evaluation of the 339 hits, a kinetic plot in which the $y$-axis shows fluorescent signals, and the $x$-axis shows timepoints was drawn for each hit. In addition, signals from 10 wells that were before and after the hit well in a 384-well plate were plotted in the same graph with the hit. Because the wells were close to each other, their reaction time was similar and thus one would expect their curves overlap if there was no inhibition of the reaction. And a real hit would produce lower signal than the neighbouring wells. We manually inspected the curves for all the 339 hits and confirmed that 142 of them gave an obvious lower signal than their neighbouring wells.

To be used as a reference for the hit selection method described above, the $Z$-score was calculated for each compound (Supplementary Figure S3G) as following:

$$
Z-\text { score }=\left[\text { Corrected } \_V_{0} \text { of } \_ \text {a } \_ \text {compound }-\operatorname{mean}\left(\operatorname{Corrected}_{-} V_{0}\right)\right] / \operatorname{SD}\left(\text { Corrected }_{-} V_{0}\right) \text {, }
$$

where mean $\left(\right.$ Corrected_ $\left.V_{0}\right)$ is the average of corrected initial velocity values of all compounds and SD (Corrected_ $V_{0}$ ) is the standard deviation of corrected initial velocity values of all compounds.

To assess the quality of the screen, the $Z$-factor was calculated for each plate based on corrected initial velocity values as following:

$$
\begin{aligned}
& Z \text { - factor } \\
& \left.\quad=1-\left[3 * \mathrm{SD}\left(\text { Corrected. } V_{0} \text {.of } . \mathrm{DMSO}\right) 3 * \mathrm{SD}(\text { no.enzyme })\right] /\left[\text { mean }\left(\text { Corrected. } V_{0} \text {.of.DMSO }\right)-\text { mean (no.enzyme }\right)\right]
\end{aligned}
$$

The average $Z$-factor for the screen after positional correction is 0.53 . This value suggests the screen is good, as described by Zhang et al. [76].

\section{Tested drugs}

SSYA001-10, myricetin and remdesivir together with the compounds selected for in vitro validation and cellbased studies were purchased and resuspended following the manufacturer's instructions. See Supplementary Table S4 for more details.

\section{Gel-based helicase assays}

A compound volume of $0.5 \mu \mathrm{l}$ at a concentration of $300 \mu \mathrm{M}$ was incubated with $5 \mu \mathrm{l}$ protein mix containing $4 \mathrm{nM} \mathrm{FH}$-nsp13 for $10 \mathrm{~min}$ at room temperature. The reaction was started by adding $5 \mu \mathrm{l}$ substrate mix containing $100 \mathrm{nM}$ forked RNA substrate (Cy3 RNA strand and unlabelled $5^{\prime}$ overhang RNA strand) and $4 \mathrm{mM}$ ATP in a reaction buffer containing $20 \mathrm{mM}$ HEPES pH 7.6, $5 \mathrm{mM} \mathrm{MgCl}_{2}, 20 \mathrm{mM} \mathrm{NaCl}, 1 \mathrm{mM}$ DTT, $0.1 \mathrm{mg} /$ $\mathrm{ml}$ BSA and $0.01 \%$ Triton X-100. The reaction mix also contained $1 \mu \mathrm{M}$ unlabelled 15-mer RNA as a competitor to trap the displaced overhang strand. After $5 \mathrm{~min}$ at room temperature, the reaction was quenched by adding $5 \mu \mathrm{l}$ quenching buffer ( $20 \mathrm{mM}$ EDTA, $0.5 \% \mathrm{SDS}, 2 \mathrm{mg} / \mathrm{ml}$ proteinase $\mathrm{K}, 10 \%$ glycerol) and incubating at $37^{\circ} \mathrm{C}$ for $5 \mathrm{~min}$. Reaction products were then analysed by running on a $20 \%$ non-denaturing PAGE gel in $0.5 \times$ TBE buffer (Life Technologies) for $20 \mathrm{~min}$ at room temperature and $200 \mathrm{~V}$. An Amersham Imager 600 was used to image $\mathrm{Cy} 3$ fluorescence.

\section{SARS-CoV-2 production}

Fifty percent confluent monolayers of Vero E6 cells (courtesy of National Institute for Biological Standards and Control, NIBSC) were infected with the SARS-CoV-2 strain England/2/2020 (courtesy of Public Health England, PHE) at an MOI of approximately 0.001. Cells were washed once with DMEM (Sigma; D6429), then $5 \mathrm{ml}$ virus inoculum made up in DMEM was added to each T175 flask and incubated at room temperature for 30 min. DMEM $+1 \%$ FCS (Biosera; FB-1001/500) was added to each flask. Cells were incubated at $37^{\circ} \mathrm{C}, 5 \%$ $\mathrm{CO}_{2}$ for 4 days until an extensive cytopathogenic effect was observed. The supernatant was harvested and clarified by centrifugation at $2000 \mathrm{rpm}$ for $10 \mathrm{~min}$ in a benchtop centrifuge. The supernatant was aliquoted and frozen at $-80^{\circ} \mathrm{C}$. 


\section{Recombinant mAb production}

Heavy and light chain variable regions for CR3009, were synthesized (Genewiz) based on the GenBank sequences with regions of overlap to restriction digested human IgG1 vectors for assembly cloning (NEB) to produce plasmids: CR3009HC and CR3001KC. N protein specific mAb CR3009 was produced by co-transfecting Expi293F cells (Life Technologies) in suspension growing at $37^{\circ} \mathrm{C}$ in $8 \% \mathrm{CO}_{2}$ atmosphere in FreeStyle $293 \mathrm{~T}$ medium (Life Technologies) with the plasmids. The supernatants were harvested 6-8 days post-transfection. as per the original study describing this mAb [77]. The CR3009 Mab were purified by affinity chromatography using a $5 \mathrm{ml}$ Protein G column (Cytiva) attached to an AKTA Pure system. Upon loading, the column was washed with PBS and bound mAbs were eluted with $0.1 \mathrm{M}$ glycine $\mathrm{pH} 2.2$ and immediately neutralized with $1 \mathrm{M}$ Tris, $\mathrm{pH}$ 8.0. The mAb-containing fractions were pooled and subjected to size exclusion chromatography using a Superdex200 16/600 prep grade column. The purified mAb CR3009 was labelled with Alexa Fluor 488-NHS (Cat\#1812 Jena Biosciences) according to the instructions from the manufacturer.

\section{Viral inhibition assay}

A $1.5 \times 10^{3}$ Vero E6 cells (NIBC, U.K.) resuspended in DMEM containing 10\% FBS were seeded into each well of 96 -well imaging plates (Greiner 655090) and cultured overnight at $37 \mathrm{C}$ and $5 \% \mathrm{CO}_{2}$. The next day, a $5 \times$ solution of compounds were generated by dispensing $10 \mathrm{mM}$ stocks of compounds into a v-bottom 96-well plate (Thermo 249946) and back filling with DMSO to equalize the DMSO concentration in all wells using an Echo 550 (Labcyte) before resuspending in DMEM containing 10\% FBS. The assay plates with seeded VERO cells had the media replaced with $60 \mu \mathrm{l}$ of fresh growth media, then $20 \mu \mathrm{l}$ of the $5 \times$ compounds were stamped into the wells of the assay plates using a Biomek Fx automated liquid handler. Finally, the cells were infected by adding $20 \mu \mathrm{l}$ of SARS-CoV-2 with a final MOI of $0.5 \mathrm{PFU} /$ cell. Twenty-two hours post infection, cells were fixed, permeabilised, and stained for SARS-CoV-2 N protein using Alexa488-labelled-CR3009 antibody produced in-house (see section for Recombinant mAb production) and cellular DNA using DRAQ7 (Abcam). Whole-well imaging at $5 \times$ was carried out using an Opera Phenix (PerkinElmer) and fluorescent areas and intensity calculated using the Phenix-associated software Harmony (PerkinElmer).

\section{Data Availability Statement}

Data associated with this study has been deposited at FigShare: 10779/crick.14519277.

\section{Competing Interests}

The authors declare that there are no competing interests associated with the manuscript.

\section{CRediT Author Contribution}

John F. Diffley: Conceptualization, Formal analysis, Supervision, Funding acquisition, Methodology, Project administration, Writing - review and editing. Jingkun Zeng: Conceptualization, Data curation, Software, Formal analysis, Validation, Investigation, Visualization, Methodology, Writing - original draft, Project administration, Writing - review and editing. Florian Weissmann: Conceptualization, Data curation, Formal analysis, Validation, Investigation, Visualization, Methodology, Writing - original draft, Writing - review and editing. Agustina P. Bertolin: Conceptualization, Data curation, Formal analysis, Validation, Investigation, Visualization, Methodology, Writing - original draft, Writing - review and editing. Viktor Posse: Conceptualization, Formal analysis, Validation, Investigation, Visualization, Methodology, Writing - review and editing. Berta Canal: Conceptualization, Investigation, Methodology, Writing - review and editing. Rachel Ulferts: Conceptualization, Investigation, Writing - review and editing. Mary Wu: Investigation. Ruth Harvey: Resources, Investigation. Saira Hussain: Resources. Jennifer C. Milligan: Resources, Investigation. Chloe Roustan: Resources, Investigation. Annabel Borg: Resources, Supervision. laura mccoy: Resources. Lucy S. Drury: Resources. Svend Kjær: Resources, Supervision. John Mccauley: Resources, Supervision. Michael Howell: Resources, Supervision. Rupert Beale: Resources, Supervision.

\section{Open Access Statement}

Open access for this article was enabled by the participation of The Francis Crick Institute in an all-inclusive Read \& Publish pilot with Portland Press and the Biochemical Society under a transformative agreement with JISC. 


\section{Funding}

This work was supported by the Francis Crick Institute, which receives its core funding from Cancer Research U.K. (FC001066, FC001030), the U.K. Medical Research Council (FC001030), and the Wellcome Trust (FC001066, FC001030). This work was also funded by a Wellcome Trust Senior Investigator Award (106252/Z/14/Z) to J.F.X. D. F.W. and B.C. have received funding from the European Union's Horizon 2020 research and innovation programme under the Marie Skłodowska-Curie grant agreement Nos. 844211 and 895786. J.Z. has received funding from a Ph.D. fellowship awarded by Boehringer Ingelheim Fonds.

\section{Acknowledgement}

We thank Anne Early for assistance.

\section{Abbreviations}

FRET, fluorescence resonance energy transfer; HTS, high-throughput screening; RdRp, RNA-dependent RNA polymerase.

\section{References}

1 World-Health-Organization. COVID19 - Numbers at a glance, https://www.who.int/emergencies/diseases/novel-coronavirus-2019. Accessed 28th February 2021

2 Weisblum, Y., Schmidt, F., Zhang, F., DaSilva, J., Poston, D., Lorenzi, J.C. et al. (2020) Escape from neutralizing antibodies by SARS-CoV-2 spike protein variants. elife $\mathbf{9}$, e61312 https://doi.org/10.7554/eLife.61312

3 Tillett, R.L., Sevinsky, J.R., Hartley, P.D., Kerwin, H., Crawford, N., Gorzalski, A. et al. (2021) Genomic evidence for reinfection with SARS-CoV-2: a case study. Lancet Infect. Dis. 21, 52-58 https://doi.org/10.1016/S1473-3099(20)30764-7

4 Dai, L. and Gao, G.F. (2020) Viral targets for vaccines against COVID-19. Nat. Rev. Immunol 73-82 https://doi.org/10.1038/s41577-020-00480-0

5 Li, Q., Wu, J., Nie, J., Zhang, L., Hao, H., Liu, S. et al. (2020) The impact of mutations in SARS-CoV-2 spike on viral infectivity and antigenicity. Cell 182, 1284-1294.e9 https://doi.org/10.1016/j.cell.2020.07.012

6 Ashburn, T.T. and Thor, K.B. (2004) Drug repositioning: identifying and developing new uses for existing drugs. Nat. Rev. Drug Discov. 3, 673-683 https://doi.org/10.1038/nrd1468

7 Guy, R.K., DiPaola, R.S., Romanelli, F. and Dutch, R.E. (2020) Rapid repurposing of drugs for COVID-19. Science 368, 829-830 https://doi.org/10. 1126/science.abb9332

8 Mulangu, S., Dodd, L.E., Davey, Jr, R.T., Tshiani Mbaya, O., Proschan, M., Mukadi, D. et al. (2019) A randomized, controlled trial of ebola virus disease therapeutics. N. Engl. J. Med. 381, 2293-2303 https://doi.org/10.1056/NEJMoa1910993

9 Warren, T.K., Jordan, R., Lo, M.K., Ray, A.S., Mackman, R.L., Soloveva, V. et al. (2016) Therapeutic efficacy of the small molecule GS-5734 against Ebola virus in rhesus monkeys. Nature 531, 381-385 https://doi.org/10.1038/nature17180

10 Beigel, J.H., Tomashek, K.M., Dodd, L.E., Mehta, A.K., Zingman, B.S., Kalil, A.C. et al. (2020) Remdesivir for the treatment of covid-19 - final report. N. Engl. J. Med. 383, 1813-1826 https://doi.org/10.1056/NEJMoa2007764

11 Kokic, G., Hillen, H.S., Tegunov, D., Dienemann, C., Seitz, F., Schmitzova, J. et al. (2021) Mechanism of SARS-CoV-2 polymerase stalling by remdesivir. Nat. Commun. 12, 279 https://doi.org/10.1038/s41467-020-20542-0

12 Wang, M., Cao, R., Zhang, L., Yang, X., Liu, J., Xu, M. et al. (2020) Remdesivir and chloroquine effectively inhibit the recently emerged novel coronavirus (2019-nCoV) in vitro. Cell Res. 30, 269-271 https://doi.org/10.1038/s41422-020-0282-0

13 Duffy, S. (2018) Why are RNA virus mutation rates so damn high? PLoS Biol. 16, e3000003 https://doi.org/10.1371/journal.pbio.3000003

14 Pachetti, M., Marini, B., Benedetti, F., Giudici, F., Mauro, E., Storici, P. et al. (2020) Emerging SARS-CoV-2 mutation hot spots include a novel RNA-dependent-RNA polymerase variant. J. Transl. Med. 18, 179 https://doi.org/10.1186/s12967-020-02344-6

15 V'Kovski, P., Kratzel, A., Steiner, S., Stalder, H. and Thiel, V. (2021) Coronavirus biology and replication: implications for SARS-CoV-2. Nat. Rev. Microbiol. 19, 155-170 https://doi.org/10.1038/s41579-020-00468-6

16 Kim, D., Lee, J.Y., Yang, J.S., Kim, J.W., Kim, V.N. and Chang, H. (2020) The architecture of SARS-CoV-2 transcriptome. Cell 181, 914-921.e10 https://doi.org/10.1016/j.cell.2020.04.011

17 Fairman-Williams, M.E., Guenther, U.P. and Jankowsky, E. (2010) SF1 and SF2 helicases: family matters. Curr. Opin. Struct. Biol. 20, 313-324 https://doi.org/10.1016/j.sbi.2010.03.011

18 Ivanov, K.A., Thiel, V., Dobbe, J.C., van der Meer, Y., Snijder, E.J. and Ziebuhr, J. (2004) Multiple enzymatic activities associated with severe acute respiratory syndrome coronavirus helicase. J. Virol. 78, 5619-5632 https://doi.org/10.1128/JVI.78.11.5619-5632.2004

19 Seybert, A., Hegyi, A., Siddell, S.G. and Ziebuhr, J. (2000) The human coronavirus 229E superfamily 1 helicase has RNA and DNA duplex-unwinding activities with 5'-to-3' polarity. RNA 6, 1056-1068 https://doi.org/10.1017/S1355838200000728

20 Tanner, J.A., Watt, R.M., Chai, Y.B., Lu, L.Y., Lin, M.C., Peiris, J.S. et al. (2003) The severe acute respiratory syndrome (SARS) coronavirus NTPase/ helicase belongs to a distinct class of $5^{\prime}$ to $3^{\prime}$ viral helicases. J. Biol. Chem. 278, 39578-39582 https://doi.org/10.1074/jbc.C300328200

21 Mickolajczyk, K.J., Shelton, P.M.M., Grasso, M., Cao, X., Warrington, S.E., Aher, A. et al. (2021) Force-dependent stimulation of RNA unwinding by SARS-CoV-2 nsp13 helicase. Biophys. J. 120, 1020-1030 https://doi.org/10.1016/j.bpj.2020.11.2276

22 Ivanov, K.A. and Ziebuhr, J. (2004) Human coronavirus 229E nonstructural protein 13: characterization of duplex-unwinding, nucleoside triphosphatase, and RNA 5'-triphosphatase activities. J. Virol. 78, 7833-7838 https://doi.org/10.1128/JVl.78.14.7833-7838.2004

23 Wu, A., Peng, Y., Huang, B., Ding, X., Wang, X., Niu, P. et al. (2020) Genome composition and divergence of the novel coronavirus (2019-nCoV) originating in China. Cell Host Microbe 27, 325-328 https://doi.org/10.1016/j.chom.2020.02.001 
24 Frick, D.N. and Lam, A.M. (2006) Understanding helicases as a means of virus control. Curr. Pharm. Des. 12, 1315-1338 https://doi.org/10.2174/ 138161206776361147

25 Seybert, A., Posthuma, C.C., van Dinten, L.C., Snijder, E.J., Gorbalenya, A.E. and Ziebuhr, J. (2005) A complex zinc finger controls the enzymatic activities of nidovirus helicases. J. Virol. 79, 696-704 https://doi.org/10.1128/JVI.79.2.696-704.2005

26 Fang, S., Chen, B., Tay, F.P., Ng, B.S. and Liu, D.X. (2007) An arginine-to-proline mutation in a domain with undefined functions within the helicase protein (Nsp13) is lethal to the coronavirus infectious bronchitis virus in cultured cells. Virology 358, 136-147 https://doi.org/10.1016/j.virol.2006.08. 020

27 Chen, J., Malone, B., Llewellyn, E., Grasso, M., Shelton, P.M.M., Olinares, P.D.B. et al. (2020) Structural basis for helicase-polymerase coupling in the SARS-CoV-2 replication-transcription complex. Cell 182, 1560-1567.e13 https://doi.org/10.1016/..cell.2020.07.033

28 Adedeji, A.O., Marchand, B., Te Velthuis, A.J., Snijder, E.J., Weiss, S., Eoff, R.L. et al. (2012) Mechanism of nucleic acid unwinding by SARS-CoV helicase. PLoS One 7, e36521 https://doi.org/10.1371/journal.pone.0036521

29 Adedeji, A.O., Singh, K. and Sarafianos, S.G. (2012) Structural and biochemical basis for the difference in the helicase activity of two different constructs of SARS-CoV helicase. Cell. Mol. Biol. (Noisy-le-grand) 58, 114-121 PMID: 23273200

30 Lee, N.R., Kwon, H.M., Park, K., Oh, S., Jeong, Y.J. and Kim, D.E. (2010) Cooperative translocation enhances the unwinding of duplex DNA by SARS coronavirus helicase nsP13. Nucleic Acids Res. 38, 7626-7636 https://doi.org/10.1093/nar/gkq647

31 Hao, W., Wojdyla, J.A., Zhao, R., Han, R., Das, R., Zlatev, I. et al. (2017) Crystal structure of Middle East respiratory syndrome coronavirus helicase. PLoS Pathog. 13, e1006474 https://doi.org/10.1371/journal.ppat.1006474

32 McGovern, S.L., Caselli, E., Grigorieff, N. and Shoichet, B.K. (2002) A common mechanism underlying promiscuous inhibitors from virtual and high-throughput screening. J. Med. Chem. 45, 1712-1722 https://doi.org/10.1021/jm010533y

33 Auld, D.S., Inglese, J., Dahlin, and J.L. (2004) Assay Interference by Aggregation. In Assay Guidance Manual (Markossian, S., Sittampalam, G.S. Grossman, A., Brimacombe, K., Arkin, M., Auld, D. et al., eds), pp. 1009-1034, Eli Lilly \& Company and the National Center for Advancing Translational Sciences, Bethesda, MD

34 Reker, D., Bernardes, G.J.L. and Rodrigues, T. (2019) Computational advances in combating colloidal aggregation in drug discovery. Nat. Chem. 11, 402-418 https://doi.org/10.1038/s41557-019-0234-9

35 Aldrich, C., Bertozzi, C., Georg, G.I., Kiessling, L., Lindsley, C., Liotta, D. et al. (2017) The ecstasy and agony of assay interference compounds. ACS Chem. Biol. 12, 575-578 https://doi.org/10.1021/acschembio.7b00119

36 Feng, B.Y. and Shoichet, B.K. (2006) A detergent-based assay for the detection of promiscuous inhibitors. Nat. Protoc. 1, 550-553 https://doi.org/10. 1038/nprot.2006.77

37 Irwin, J.J., Duan, D., Torosyan, H., Doak, A.K., Ziebart, K.T., Sterling, T. et al. (2015) An aggregation advisor for ligand discovery. J. Med. Chem. 58 7076-7087 https://doi.org/10.1021/acs.jmedchem.5b01105

38 Adedeji, A.O., Singh, K., Calcaterra, N.E., DeDiego, M.L., Enjuanes, L., Weiss, S. et al. (2012) Severe acute respiratory syndrome coronavirus replication inhibitor that interferes with the nucleic acid unwinding of the viral helicase. Antimicrob. Agents Chemother. 56, 4718-4728 https://doi.org/10.1128/ AAC.00957-12

39 Adedeji, A.O., Singh, K., Kassim, A., Coleman, C.M., Elliott, R., Weiss, S.R. et al. (2014) Evaluation of SSYA10-001 as a replication inhibitor of severe acute respiratory syndrome, mouse hepatitis, and Middle East respiratory syndrome coronaviruses. Antimicrob. Agents Chemother. 58, 4894-4898 https://doi.org/10.1128/AAC.02994-14

40 Yu, M.S., Lee, J., Lee, J.M., Kim, Y., Chin, Y.W., Jee, J.G. et al. (2012) Identification of myricetin and scutellarein as novel chemical inhibitors of the SARS coronavirus helicase, nsP13. Bioorg. Med. Chem. Lett. 22, 4049-4054 https://doi.org/10.1016/..bmcl.2012.04.081

41 Canal, B., Fujisawa, R., McClure, A.W., Deegan, T.D., Wu, M., Ulferts, R. et al. (2021) Identifying SARS-CoV-2 antiviral compounds by screening for small molecule inhibitors of nsp15 endoribonuclease. Biochem. J. 478, https://doi.org/10.1042/BCJ20210199

42 Suzuki, E., Kessler, M., Montgomery, K. and Arai, A.C. (2004) Divergent effects of the purinoceptor antagonists suramin and pyridoxal-5'-phosphate-6-(2'-naphthylazo-6'-nitro-4',8'-disulfonate) (PPNDS) on alpha-amino-3-hydroxy-5-methyl-4-isoxazolepropionic acid (AMPA) receptors. Mol. Pharmacol. 66, 1738-1747 https://doi.org/10.1124/mol.104.003038

43 Wiedemar, N., Hauser, D.A. and Maser, P. (2020) 100 years of suramin. Antimicrob. Agents Chemother. 64, e01168-19 https://doi.org/10.1128/AAC 01168-19

44 Wu, K., Chong, R.A., Yu, Q., Bai, J., Spratt, D.E., Ching, K. et al. (2016) Suramin inhibits cullin-RING E3 ubiquitin ligases. Proc. Natl Acad. Sci. U.S.A. 113, E2011-E2018 https://doi.org/10.1073/pnas.1601089113

45 Ren, P., Zheng, Y., Wang, W., Hong, L., Delpeyroux, F., Arenzana-Seisdedos, F. et al. (2017) Suramin interacts with the positively charged region surrounding the 5-fold axis of the EV-A71 capsid and inhibits multiple enterovirus A. Sci. Rep. 7, 42902 https://doi.org/10.1038/srep42902

46 Su, L., Bryan, N., Battista, S., Freitas, J., Garabedian, A., D’Alessio, F. et al. (2020) Identification of HMGA2 inhibitors by AlphaScreen-based ultra-high-throughput screening assays. Sci. Rep. 10, 18850 https://doi.org/10.1038/s41598-020-75890-0

47 Bertolin, A.P., Weissmann, F., Zeng, J., Posse, V., Milligan, J.C., Canal, B. et al. (2021) Identifying SARS-CoV-2 antiviral compounds by screening for small molecule inhibitors of nsp12/7/8 RNA-dependent RNA polymerase. Biochem. J. 478, https://doi.org/10.1042/BCJ20210200

48 Basavannacharya, C. and Vasudevan, S.G. (2014) Suramin inhibits helicase activity of NS3 protein of dengue virus in a fluorescence-based high throughput assay format. Biochem. Biophys. Res. Commun. 453, 539-544 https://doi.org/10.1016/j.bbrc.2014.09.113

49 Croci, R., Pezzullo, M., Tarantino, D., Milani, M., Tsay, S.C., Sureshbabu, R. et al. (2014) Structural bases of norovirus RNA dependent RNA polymerase inhibition by novel suramin-related compounds. PLoS One 9, e91765 https://doi.org/10.1371/journal.pone.0091765

50 Ferla, S., Netzler, N.E., Ferla, S., Veronese, S., Tuipulotu, D.E., Guccione, S. et al. (2018) In silico screening for human norovirus antivirals reveals a novel non-nucleoside inhibitor of the viral polymerase. Sci. Rep. 8, $4129 \mathrm{https}: / /$ doi.org/10.1038/s41598-018-22303-y

51 Canal, B., McClure, A.W., Curran, J.F., Wu, M., Ulferts, R., Weissmann, F. et al. (2021) Identifying SARS-CoV-2 antiviral compounds by screening for small molecule inhibitors of Nsp14/nsp10 exoribonuclease. Biochem. J. 478, 2445-2463 https://doi.org/10.1042/BCJ20210198

52 Basu, S., Mak, T., Ulferts, R., Wu, M., Deegan, T., Fujisawa, R. et al. (2021) Identification of SARS-CoV-2 antiviral compounds by screening for small molecule inhibitors of the nsp14 RNA cap methyltransferase. Biochem. J. 478, 2481-2497 https://doi.org/10.1042/BCJ20210219 
53 Milligan, J.C., Zeisner, T.U., Papageorgiou, G., Joshi, D., Soudy, C., Ulferts, R. et al. (2021) Identifying SARS-CoV-2 antiviral compounds by screening for small molecule inhibitors of nsp5 main protease. Biochem. J. 478, 2499-2515 https://doi.org/10.1042/BCJ20210197

54 Lim, C.T., Tan, K.W., Wu, M., Ulferts, R., Armstrong, L.A., Ozono, E. et al. (2021) Identifying SARS-CoV-2 antiviral compounds by screening for small molecule inhibitors of Nsp3 papain-like protease. Biochem. J. 478, 2517-2531 https://doi.org/10.1042/BCJ20210244

55 Barve, V., Ahmed, F., Adsule, S., Banerjee, S., Kulkarni, S., Katiyar, P. et al. (2006) Synthesis, molecular characterization, and biological activity of novel synthetic derivatives of chromen-4-one in human cancer cells. J. Med. Chem. 49, 3800-3808 https://doi.org/10.1021/jm051068y

56 Al-Lazikani, B., Banerji, U. and Workman, P. (2012) Combinatorial drug therapy for cancer in the post-genomic era. Nat. Biotechnol. 30, 679-692 https://doi.org/10.1038/nbt.2284

57 Yan, L., Zhang, Y., Ge, J., Zheng, L., Gao, Y., Wang, T. et al. (2020) Architecture of a SARS-CoV-2 mini replication and transcription complex. Nat. Commun. 11, $5874 \mathrm{https://doi.org/10.1038/s41467-020-19770-1}$

58 Seidler, J., McGovern, S.L., Doman, T.N. and Shoichet, B.K. (2003) Identification and prediction of promiscuous aggregating inhibitors among known drugs. J. Med. Chem. 46, 4477-4486 https://doi.org/10.1021/jm030191r

59 Babaoglu, K., Simeonov, A., Irwin, J.J., Nelson, M.E., Feng, B., Thomas, C.J. et al. (2008) Comprehensive mechanistic analysis of hits from high-throughput and docking screens against beta-lactamase. J. Med. Chem. 51, 2502-2511 https://doi.org/10.1021/jm701500e

60 Ferreira, R.S., Simeonov, A., Jadhav, A., Eidam, O., Mott, B.T., Keiser, M.J. et al. (2010) Complementarity between a docking and a high-throughput screen in discovering new cruzain inhibitors. J. Med. Chem. 53, 4891-4905 https://doi.org/10.1021/jm100488w

61 Pohjala, L. and Tammela, P. (2012) Aggregating behavior of phenolic compounds-a source of false bioassay results? Molecules 17, 10774-10790 https://doi.org/10.3390/molecules170910774

62 Klann, K., Bojkova, D., Tascher, G., Ciesek, S., Munch, C. and Cinatl, J. (2020) Growth factor receptor signaling inhibition prevents SARS-CoV-2 replication. Mol. Cell 80, 164-174.e4 https://doi.org/10.1016/j.molcel.2020.08.006

63 Garcia G, J., Sharma, A., Ramaiah, A., Sen, C., Purkayastha, A., Kohn, D.B. et al. (2021) Antiviral drug screen identifies DNA-damage response inhibitor as potent blocker of SARS-CoV-2 replication. Cell Rep. 35, 108940 https://doi.org/10.1016/..celrep.2021.108940

64 Brun, R., Blum, J., Chappuis, F. and Burri, C. (2010) Human African trypanosomiasis. Lancet 375, 148-159 https://doi.org/10.1016/S0140-6736(09) 60829-1

65 Salgado-Benvindo, C., Thaler, M., Tas, A., Ogando, N.S., Bredenbeek, P.J., Ninaber, D.K. et al. (2020) Suramin inhibits SARS-CoV-2 infection in cell culture by interfering with early steps of the replication cycle. Antimicrob. Agents Chemother. 64, e00900-20 https://doi.org/10.1128/AAC.00900-20

66 Ren, P., Zou, G., Bailly, B., Xu, S., Zeng, M., Chen, X. et al. (2014) The approved pediatric drug suramin identified as a clinical candidate for the treatment of EV71 infection-suramin inhibits EV71 infection in vitro and in vivo. Emerg. Microbes Infect. 3, e62 https://doi.org/10.1038/emi.2014.60

67 Nishimura, Y., McLaughlin, N.P., Pan, J., Goldstein, S., Hafenstein, S., Shimizu, H. et al. (2015) The suramin derivative NF449 interacts with the 5 -fold vertex of the enterovirus A71 capsid to prevent virus attachment to PSGL-1 and heparan sulfate. PLoS Pathog. 11, e1005184 https://doi.org/10.1371/ journal.ppat.1005184

68 Mastrangelo, E., Pezzullo, M., Tarantino, D., Petazzi, R., Germani, F., Kramer, D. et al. (2012) Structure-based inhibition of norovirus RNA-dependent RNA polymerases. J. Mol. Biol. 419, 198-210 https://doi.org/10.1016/j.jmb.2012.03.008

69 Mastrangelo, E., Mazzitelli, S., Fabbri, J., Rohayem, J., Ruokolainen, J., Nykanen, A. et al. (2014) Delivery of suramin as an antiviral agent through liposomal systems. ChemMedChem 9, 933-939 https://doi.org/10.1002/cmdc.201300563

70 Grein, J., Ohmagari, N., Shin, D., Diaz, G., Asperges, E., Castagna, A. et al. (2020) Compassionate use of remdesivir for patients with severe Covid-19. N. Engl. J. Med. 382, 2327-2336 https://doi.org/10.1056/NEJMoa2007016

71 Zheng, W., Sun, W. and Simeonov, A. (2018) Drug repurposing screens and synergistic drug-combinations for infectious diseases. Br. J. Pharmacol. 175, 181-191 https://doi.org/10.1111/bph.13895

72 Gordon, D.E., Jang, G.M., Bouhaddou, M., Xu, J., Obernier, K., White, K.M. et al. (2020) A SARS-CoV-2 protein interaction map reveals targets for drug repurposing. Nature 583, 459-468 https://doi.org/10.1038/s41586-020-2286-9

73 Desmyter, J., Melnick, J.L. and Rawls, W.E. (1968) Defectiveness of interferon production and of rubella virus interference in a line of African green monkey kidney cells (Vero). J. Virol. 2, 955-961 https://doi.org/10.1128/JVI.2.10.955-961.1968

74 Weissmann, F., Petzold, G., VanderLinden, R., Huis In 't Veld, P.J., Brown, N.G., Lampert, F. et al. (2016) biGBac enables rapid gene assembly for the expression of large multisubunit protein complexes. Proc. Natl Acad. Sci. U.S.A. 113, E2564-E2569 https://doi.org/10.1073/pnas.1604935113

75 Trowitzsch, S., Bieniossek, C., Nie, Y., Garzoni, F. and Berger, I. (2010) New baculovirus expression tools for recombinant protein complex production. J. Struct. Biol. 172, 45-54 https://doi.org/10.1016/j.jsb.2010.02.010

76 Zhang, J.H., Chung, T.D. and Oldenburg, K.R. (1999) A simple statistical parameter for use in evaluation and validation of high throughput screening assays. J. Biomol. Screen. 4, 67-73 https://doi.org/10.1177/108705719900400206

77 van den Brink, E.N., Ter Meulen, J., Cox, F., Jongeneelen, M.A., Thijsse, A., Throsby, M. et al. (2005) Molecular and biological characterization of human monoclonal antibodies binding to the spike and nucleocapsid proteins of severe acute respiratory syndrome coronavirus. J. Virol. 79, 1635-1644 https://doi.org/10.1128/JVI.79.3.1635-1644.2005 